\title{
A decadal satellite record of gravity wave activity in the lower stratosphere to study polar stratospheric cloud formation
}

\author{
Lars Hoffmann $^{1}$, Reinhold Spang ${ }^{2}$, Andrew Orr ${ }^{3}$, M. Joan Alexander ${ }^{4}$, Laura A. Holt ${ }^{4}$, and Olaf Stein ${ }^{1}$ \\ ${ }^{1}$ Jülich Supercomputing Centre, Forschungszentrum Jülich, Jülich, Germany \\ ${ }^{2}$ Institut für Energie- und Klimaforschung, Forschungszentrum Jülich, Jülich, Germany \\ ${ }^{3}$ British Antarctic Survey, NERC, Cambridge, UK \\ ${ }^{4}$ NorthWest Research Associates, Inc., CoRA Office, Boulder, CO, USA \\ Correspondence to: Lars Hoffmann (1.hoffmann@fz-juelich.de)
}

Received: 22 August 2016 - Discussion started: 5 September 2016

Revised: 7 December 2016 - Accepted: 6 February 2017 - Published: 24 February 2017

\begin{abstract}
Atmospheric gravity waves yield substantial small-scale temperature fluctuations that can trigger the formation of polar stratospheric clouds (PSCs). This paper introduces a new satellite record of gravity wave activity in the polar lower stratosphere to investigate this process. The record is comprised of observations of the Atmospheric Infrared Sounder (AIRS) aboard NASA's Aqua satellite from January 2003 to December 2012. Gravity wave activity is measured in terms of detrended and noise-corrected $15 \mu \mathrm{m}$ brightness temperature variances, which are calculated from AIRS channels that are the most sensitive to temperature fluctuations at about $17-32 \mathrm{~km}$ of altitude. The analysis of temporal patterns in the data set revealed a strong seasonal cycle in wave activity with wintertime maxima at mid- and high latitudes. The analysis of spatial patterns indicated that orography as well as jet and storm sources are the main causes of the observed waves. Wave activity is closely correlated with $30 \mathrm{hPa}$ zonal winds, which is attributed to the AIRS observational filter. We used the new data set to evaluate explicitly resolved temperature fluctuations due to gravity waves in the European Centre for Medium-Range Weather Forecasts (ECMWF) operational analysis. It was found that the analysis reproduces orographic and non-orographic wave patterns in the right places, but that wave amplitudes are typically underestimated by a factor of $2-3$. Furthermore, in a first survey of joint AIRS and Michelson Interferometer for Passive Atmospheric Sounding (MIPAS) satellite observations, nearly 50 gravity-wave-induced PSC formation events were identified. The survey shows that the new AIRS data set can help to better identify such events and more gener-
\end{abstract}

ally highlights the importance of the process for polar ozone chemistry.

\section{Introduction}

Polar stratospheric clouds (PSCs) play a key role in ozone chemistry in the polar lower stratosphere. The particles provide the surface area for heterogeneous reactions that catalyze the conversion of chlorine from reservoir gases like $\mathrm{ClONO}_{2}$ and $\mathrm{HCl}$ into active chlorine radicals, which accelerate ozone loss in the polar lower stratosphere in late winter and spring (Solomon et al., 1986; Solomon, 1999). Furthermore, the sedimentation of large cloud particles containing $\mathrm{HNO}_{3}$ leads to the denitrification of the stratosphere, which in turn decreases $\mathrm{NO}_{2}$ concentrations, increases $\mathrm{ClO} / \mathrm{ClONO}_{2}$ ratios, and accelerates chlorinecatalyzed ozone loss (Toon et al., 1986). PSC particles are typically classified into three different types (Poole and McCormick, 1988; Browell et al., 1990). This includes metastable hydrates of $\mathrm{HNO}_{3}$, such as nitric acid trihydrate (NAT) (Hanson and Mauersberger, 1988; Worsnop et al., 1993), supercooled ternary solution (STS) droplets of $\mathrm{H}_{2} \mathrm{SO}_{4} / \mathrm{HNO}_{3} / \mathrm{H}_{2} \mathrm{O}$ (Zhang et al., 1993; Carslaw et al., 1994), and water ice (Steele et al., 1983). Thermodynamic analyses indicate that NAT and STS can exist at temperatures well above the frost point of ice with $T_{\text {ice }}<T_{\text {STS }}<$ $T_{\text {NAT }}$. Typical PSC formation and existence temperatures at $20 \mathrm{~km}$ of altitude are $T_{\text {ice }}=188 \mathrm{~K}, T_{\mathrm{STS}}=191 \mathrm{~K}$, and 
$T_{\text {NAT }}=195 \mathrm{~K}$ (Pawson et al., 1995). However, actual values vary with atmospheric composition and altitude.

Atmospheric gravity waves are an important driver of middle atmosphere dynamics and have a substantial impact on weather and climate. They transport energy and momentum from lower to upper altitudes, contribute to turbulence and mixing, and influence the mean circulation and thermal structure of the middle atmosphere (Lindzen, 1981; Holton, 1982). Gravity waves are triggered by a variety of sources. The most prominent sources are orography (Smith, 1985; Durran and Klemp, 1987; Nastrom and Fritts, 1992) and convection (Pfister et al., 1986; Tsuda et al., 1994; Alexander and Pfister, 1995). Other sources include the adjustment of unbalanced flows near jet streams and frontal systems (Fritts and Alexander, 2003; Wu and Zhang, 2004). Here, we are interested in gravity waves because they can provide significant local temperature fluctuations that can trigger the formation of PSCs, even if synoptic-scale temperatures are above formation thresholds. Case studies of mountain waves induced by the Scandinavian Mountains showed that the waves can cause localized cooling of up to 10-15 K (Carslaw et al., 1998b; Dörnbrack et al., 1999, 2002). The Antarctic Peninsula is another well-known hot spot for the formation of PSCs from mountain waves in the Southern Hemisphere (Wu and Jiang, 2002; Shibata et al., 2003; Höpfner et al., 2006b; Baumgaertner and McDonald, 2007; Eckermann et al., 2009; Orr et al., 2015). In the Antarctic polar stratosphere, waveinduced PSC formation is particularly important in fall or spring, whereas synoptic-scale temperatures in winter are usually well below the PSC formation threshold (Campbell and Sassen, 2008; McDonald et al., 2009; Noel and Pitts, 2012). The Arctic stratospheric vortex is generally warmer and more disturbed due to planetary wave activity, possibly making gravity waves an even more important source of PSCs in the Northern Hemisphere (Alexander et al., 2013). Although most case studies focus on gravity waves from orographic sources, Hitchman et al. (2003) and Shibata et al. (2003) showed that non-orographic gravity waves can also trigger PSC formation.

Previous studies on PSC formation used mesoscale model output (Höpfner et al., 2006a; Noel and Pitts, 2012; Orr et al., 2015) or global positioning system radio occultation observations (Kohma and Sato, 2011; Alexander et al., 2011, 2013) as a source of information on gravity waves. The use of Atmospheric Infrared Sounder (AIRS) observations for that purpose was first explored by Eckermann et al. (2009) and Lambert et al. (2012). In this paper, we present a new AIRS data set on gravity wave activity in the polar lower stratosphere that can be used to study the impact of gravity-waveinduced temperature fluctuations on PSC formation in more detail. The data set is based on a 10-year record (January 2003 to December 2012) of observations and includes more than $5.3 \times 10^{9}$ infrared radiance spectra measured by AIRS at mid- and high latitudes during that time. As a measure of gravity wave activity, the new data set provides daily, de- trended, and noise-corrected $15 \mu \mathrm{m}$ brightness temperature variances on a $4^{\circ} \times 2^{\circ}$ longitude-latitude grid. The AIRS channels selected for the data product provide the most sensitivity in the lower and mid-stratosphere (about $17-32 \mathrm{~km}$ ), i.e., in the altitude range that is most relevant for PSC formation. We used the new AIRS data set to identify local hot spots and sources of gravity wave activity, to characterize its seasonal cycle at northern and southern mid- and high latitudes, and to analyze correlations with stratospheric background winds.

We exploited the new AIRS data set in two applications. Various studies have demonstrated that AIRS measurements are particularly suited to validating high-resolution gravity wave simulations. Some studies focused on the validation of convective waves (Kim et al., 2009; Grimsdell et al., 2010; Stephan and Alexander, 2015; Wu et al., 2015), but case studies for mountain waves have also been conducted (Orr et al., 2015). The validation of explicitly resolved temperature fluctuations in high-resolution meteorological analyses is of particular interest to Lagrangian studies that could potentially use these data to study PSC formation (Engel et al., 2013; Hoyle et al., 2013; Grooß et al., 2014; Di Liberto et al., 2015). We used the AIRS data to evaluate explicitly resolved temperature fluctuations due to gravity waves in the European Centre for Medium-Range Weather Forecasts (ECMWF) operational analysis for a set of 21 large-amplitude gravity wave events in the polar winter seasons. With the spatial resolution and physical representation of the forecast models improving over time as well as the inclusion of new observations within the assimilation procedures, it is important to know how realistically the analysis captures atmospheric gravity waves. As a second application, we performed a survey of joint AIRS gravity wave observations and PSC observations from the Michelson Interferometer for Passive Atmospheric Sounding (MIPAS) instrument (Fischer et al., 2008) aboard the ESA's Envisat satellite. The survey covers the years 2003 to 2012, while Envisat MIPAS was in operation, and provides nearly continuous monitoring of PSCs throughout the polar stratosphere. The main aim of this survey is to infer whether the new AIRS data set introduced here can help to better identify gravity-wave-induced PSC formation events and to stimulate more detailed Lagrangian case studies in future work.

In Sect. 2, we provide a description of the AIRS instrument and the method used to extract gravity wave information from the measurements. The spatial and temporal patterns of wave activity in the lower stratosphere at mid- and high latitudes as observed by AIRS are discussed in Sect. 3. The evaluation of explicitly resolved temperature fluctuations in the ECMWF operational analysis is presented in Sect. 4. We discuss selected examples and the survey of gravity-waveinduced PSC formation events based on AIRS and MIPAS data in Sect. 5. Finally, a summary and conclusions are given in Sect. 6. 

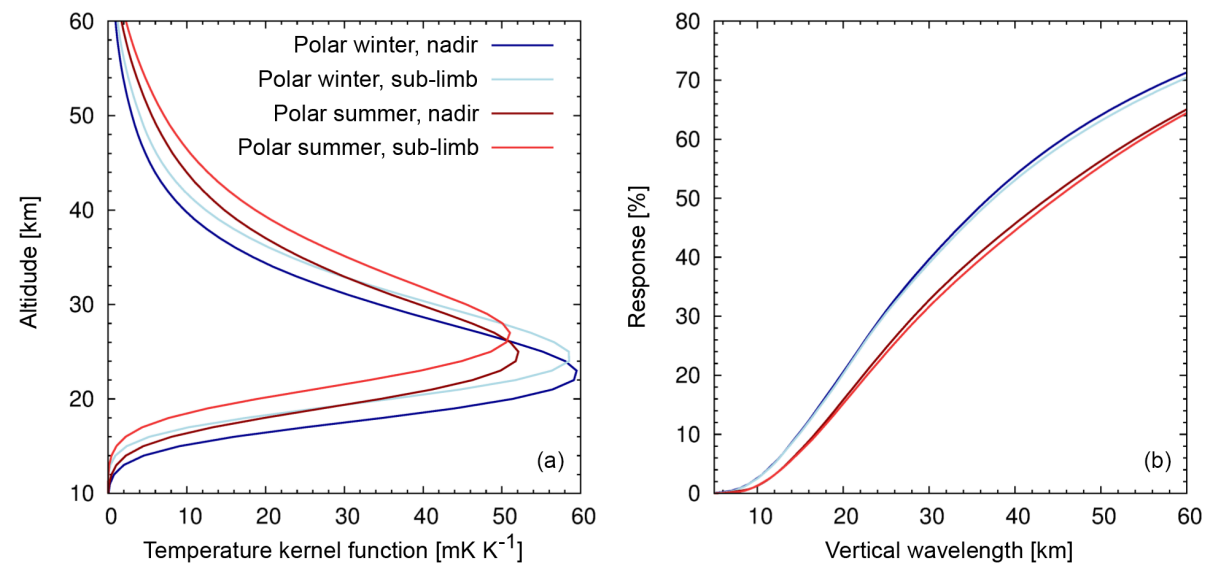

Figure 1. Temperature-weighting functions (left) and amplitude response curves (right) for the AIRS $15 \mu \mathrm{m}$ brightness temperature data set. Radiative transfer calculations have been performed for polar summer and polar winter conditions, the nadir direction and the outermost scan angles (referred to as "sub-limb"), and a $1 \mathrm{~km}$ altitude grid.

Table 1. AIRS radiance channels of the $15 \mu \mathrm{m}$ brightness temperature data product.

\begin{tabular}{lrr|lrr}
\hline $\begin{array}{l}\text { Channel } \\
\text { number }\end{array}$ & $\begin{array}{r}\text { Wave } \\
\text { number } \\
\left(\mathrm{cm}^{-1}\right)\end{array}$ & $\begin{array}{r}\text { NEdT } \\
\text { at } 250 \mathrm{~K} \\
(\mathrm{~K})\end{array}$ & $\begin{array}{l}\text { Channel } \\
\text { number }\end{array}$ & $\begin{array}{r}\text { Wave } \\
\text { number } \\
\left(\mathrm{cm}^{-1}\right)\end{array}$ & $\begin{array}{r}\text { NEdT } \\
\text { at 250 K } \\
(\mathrm{K})\end{array}$ \\
\hline 5 & 650.6 & 0.60 & 101 & 674.4 & 0.42 \\
11 & 652.0 & 0.67 & 102 & 674.7 & 0.44 \\
17 & 653.5 & 0.61 & 107 & 676.0 & 0.45 \\
23 & 654.9 & 0.61 & 108 & 676.2 & 0.42 \\
30 & 656.6 & 0.54 & 113 & 677.5 & 0.39 \\
36 & 658.1 & 0.51 & 114 & 677.8 & 0.43 \\
42 & 659.6 & 0.47 & 119 & 679.1 & 0.42 \\
56 & 663.0 & 0.46 & 120 & 679.4 & 0.45 \\
84 & 670.1 & 0.49 & 125 & 680.7 & 0.41 \\
89 & 671.3 & 0.39 & 126 & 680.9 & 0.41 \\
95 & 672.9 & 0.43 & & & \\
\hline
\end{tabular}

\section{AIRS observations of stratospheric gravity waves}

AIRS (Aumann et al., 2003; Chahine et al., 2006) is one of six instruments aboard NASA's Aqua satellite. Aqua was launched in May 2002 into a nearly polar, low earth orbit at $705 \mathrm{~km}$ of altitude, $100^{\circ}$ of inclination, and a $100 \mathrm{~min}$ orbital period. The Aqua orbit is sun-synchronous with Equator crossings at 01:30 LT (descending nodes) and 13:30 LT (ascending nodes). Nearly global coverage is achieved in 14.4 orbits per day. AIRS measures infrared radiance spectra in a cross-track scanning geometry. Each scan consists of 90 footprints and covers $1780 \mathrm{~km}$ of ground distance. The footprint size varies between $14 \times 14 \mathrm{~km}^{2}$ at the nadir and $21 \times 42 \mathrm{~km}^{2}$ at the scan extremes. Adjacent scans are separated by $18 \mathrm{~km}$ of along-track distance. The spectral measurements cover the $3.74-15.4 \mu \mathrm{m}$ wavelength range in three bands. Brightness temperature measurements in the 4.3 and $15 \mu \mathrm{m}$ wavebands of $\mathrm{CO}_{2}$ are particularly suited to studying stratospheric gravity waves (Alexander and Barnet, 2007; Hoffmann and Alexander, 2009; Gong et al., 2012; Hoffmann et al., 2014).

For this study, we identified a set of 21 AIRS channels in the $15 \mu \mathrm{m} \mathrm{CO} \mathrm{CO}_{2}$ waveband to study gravity wave activity in the polar lower stratosphere. Our channel selection differs from the earlier work of Hoffmann et al. (2013, 2014), which used AIRS channels in the $4.3 \mu \mathrm{m} \mathrm{CO} 2$ waveband to obtain gravity wave information for the mid- and upper stratosphere. The channels selected for this study are listed in Table 1 together with centroid frequencies and noise estimates (referred to as noise equivalent delta temperature; NeDT) at a $250 \mathrm{~K}$ scene temperature. The radiance measurements of the selected channels are averaged to obtain a low-noise data product. Figure 1 shows the corresponding spectral mean temperature-weighting functions for different atmospheric conditions and for different viewing directions of AIRS. The weighting function for polar winter conditions at the nadir shows maximum sensitivity to stratospheric temperatures at around $23 \mathrm{~km}$ of altitude. Its full width at half maximum is $15 \mathrm{~km}$ and extends over the altitude range from 17 to $32 \mathrm{~km}$, which provides overlap with the altitude range typically covered by PSCs (Poole and Pitts, 1994; Spang et al., 2005; Pitts et al., 2009). Comparing the weighting function for the nadir and the outermost scan angles, we found that both have nearly the same width, but the latter is shifted upward by about $2 \mathrm{~km}$. This shift is due to opacity growing more rapidly with altitude along slant ray paths. As stratospheric temperatures increase with altitude, measured radiances also increase with increasing scan angles, which is referred to as a "limbbrightening effect". Although we are mainly interested in polar winter conditions, we also calculated weighting functions for polar summer conditions to assess the influence of atmospheric variability. In polar summer, the temperatureweighting functions are slightly broader and shift upward by about $2 \mathrm{~km}$. This is due to stratospheric air density being higher in polar summer than in polar winter. 
The temperature-weighting functions can be used to calculate the amplitude response of the AIRS observations to gravity waves with different vertical wavelengths. Following the approach of Hoffmann and Alexander (2010) and Hoffmann et al. (2014), we convolve plane wave temperature perturbation profiles with known amplitude and vertical wavelength with the AIRS weighting functions. This provides simulated brightness temperature perturbations. Then the response is calculated as the ratio of the simulated brightness temperature perturbations and the true temperature amplitudes of the gravity waves. The amplitude response curves for the AIRS $15 \mu \mathrm{m}$ data set are shown in Fig. 1. The AIRS observations are limited to gravity waves with long vertical wavelengths due to the broad weighting functions of the nadir observation geometry. The amplitude responses are about 10, 20, and $50 \%$ for vertical wavelengths of about 15,20 , and $37 \mathrm{~km}$, respectively. For instance, assuming gravity waves with a vertical wavelength of $20 \mathrm{~km}$ would mean that the brightness temperature amplitudes are damped by a factor of 5 in the AIRS observations compared to the real temperature amplitudes of the gravity waves. For smaller vertical wavelengths, the attenuation will be stronger. As a consequence, brightness temperatures need to be measured with high precision to reliably detect the small perturbations caused by gravity waves. Reducing the measurement noise by spectrally averaging the radiance measurements of multiple AIRS channels helps to improve the response to gravity waves with short vertical wavelengths. Figure 1 shows that the amplitude response varies with respect to the atmospheric conditions, but there are nearly no variations with respect to the AIRS scan angle.

Slowly varying background signals need to be removed to extract gravity wave signals from the AIRS measurements. Background signals are caused not only by large-scale temperature gradients and planetary waves, but also by the limbbrightening effect. A standard detrending technique for AIRS is to remove the background defined by means of a polynomial fit to the brightness temperature measurements of each across-track scan (Wu, 2004; Eckermann et al., 2006; Alexander and Barnet, 2007; Hoffmann et al., 2014). Usually, a fourth-order polynomial is applied for this purpose. However, we identified problems with this approach in this study. Large-scale temperature gradients at the edge of the polar vortex can become rather large in the lower stratosphere and are sometimes not completely captured by the fourth-order polynomial. Therefore, we replaced the fourthorder polynomial with a sixth-order polynomial, noting that the higher-order fit is still well constrained by the measurements. The sixth-order polynomial fit reduces the amplitude response to gravity waves with long horizontal wavelengths, but it also effectively removes unwanted temperature residuals near the polar vortex edge. Following Hoffmann et al. (2014), we estimated amplitude response levels of 50, 20, and $10 \%$ at 900,1160 , and $1350 \mathrm{~km}$ across-track wavelengths, respectively (see Fig. 2). The limit for short hori-

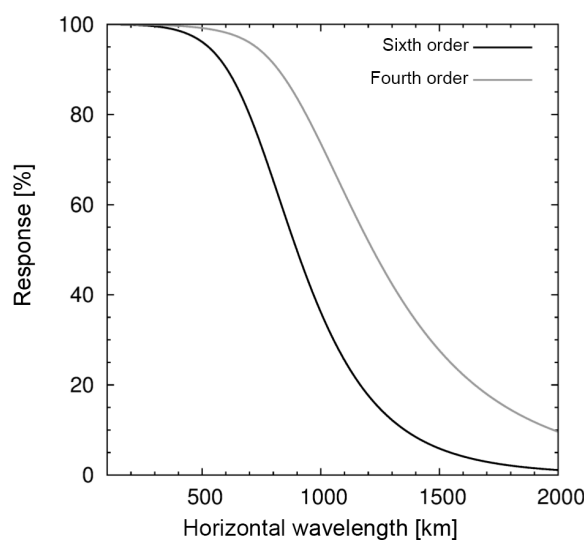

Figure 2. Amplitude response of the AIRS $15 \mu \mathrm{m}$ brightness temperature data set for gravity waves with different across-track wavelengths. The plot shows the response using a fourth- or sixth-order polynomial fit to estimate background signals.

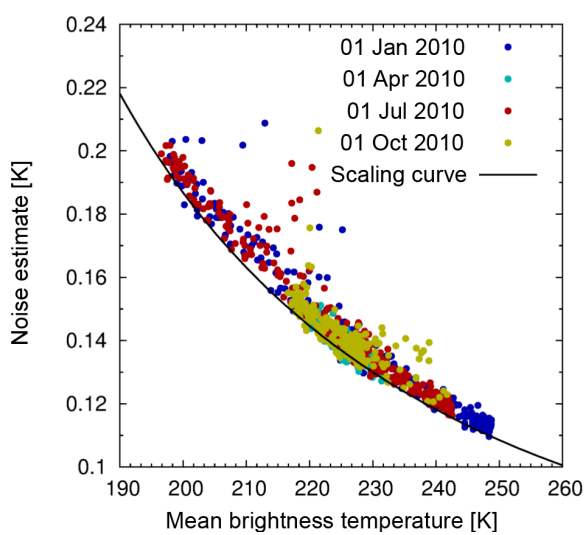

Figure 3. Noise estimates for the AIRS $15 \mu \mathrm{m}$ brightness temperature data set versus mean background temperature. Individual noise estimates (colored dots) were obtained from radiance measurements within globally distributed boxes of $90 \times 90$ satellite footprints on different days. The few outliers with high noise are due to cases of small-scale waves being misinterpreted as noise. The Planck scaling curve (black curve) is defined by a NEdT of $0.109 \mathrm{~K}$ at a $250 \mathrm{~K}$ scene temperature.

zontal wavelengths varies between 30 and $80 \mathrm{~km}$, depending on the AIRS scan angle.

The analysis of AIRS gravity wave observations requires careful characterization of measurement noise. Accurate noise estimates are particularly important if brightness temperature variances are calculated for long time periods or large regions because gravity wave signals tend to average out in this case. We applied the approach of Hoffmann et al. (2014) to estimate the noise of the AIRS $15 \mu \mathrm{m}$ brightness temperature data set directly from the measurements. Figure 3 shows that the noise estimates vary with the scene temperature. The noise typically ranges from $0.109 \mathrm{~K}$ at a $250 \mathrm{~K}$ scene temperature to $0.201 \mathrm{~K}$ at a $195 \mathrm{~K}$ scene temperature. 

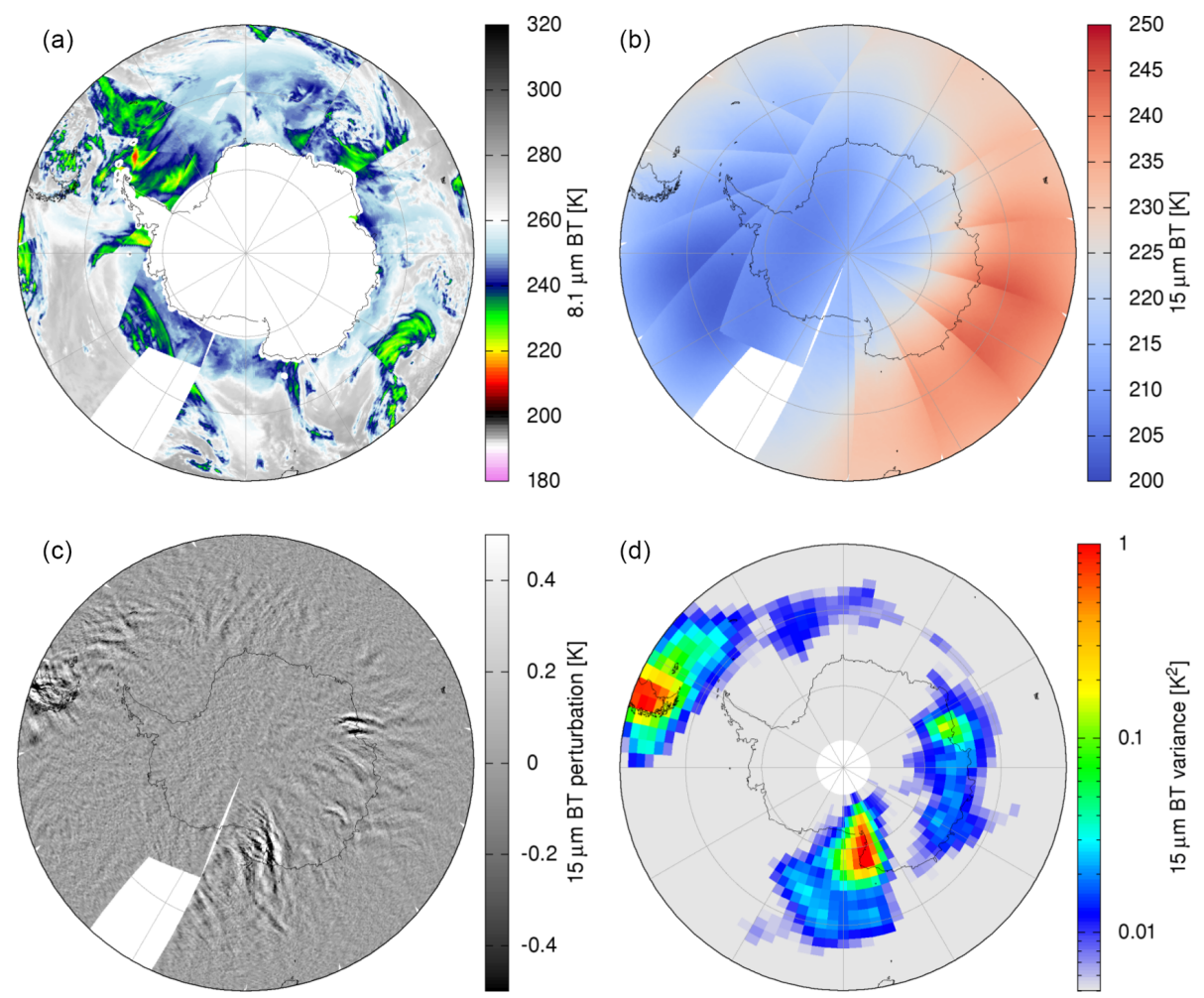

Figure 4. AIRS measurements of $8.1 \mu \mathrm{m}$ (top left) and $15 \mu \mathrm{m}$ (top right) brightness temperatures (BTs) on 24 August 2004 from 12:00 to 24:00 UTC. The $8.1 \mu \mathrm{m}$ BT observations show high clouds and storm systems. The $15 \mu \mathrm{m}$ BT perturbation map (bottom left) provides information on gravity waves in the lower stratosphere. BT variances on a $4^{\circ} \times 2^{\circ}$ longitude-latitude grid (bottom right) are calculated by combining measurements from 00:00 to 12:00 UTC (not shown) and from 12:00 to 24:00 UTC on the given day to close data gaps and to homogenize temporal coverage.

The highest noise is found in polar winter conditions, where scene temperatures are coldest and measured radiance signals are lowest. In contrast, the lowest noise occurs in polar summer conditions. Note that the noise of the spectrally averaged data set is about 4-6 times lower than the nominal noise levels of the individual AIRS channels (Table 1). This provides a substantial improvement in terms of sensitivity to gravity waves with short vertical wavelengths. Also note that the dependence of noise on the scene temperature is well characterized by a Planck scaling curve (Fig. 3). Following Hoffmann et al. (2014), this scaling curve is used in our analyses to subtract noise estimates from brightness temperature variances, so that only gravity wave signals remain. The variances are then referred to as "noise-corrected". The correction has an accuracy of about $2 \%$, which is determined by the uncertainty of fit of the Planck function.

As an example, Fig. 4 shows AIRS measurements at both 8.1 and $15 \mu \mathrm{m}$ wavelengths on 24 August 2004. This particular day is characterized by rather strong gravity wave activity at southern mid- and high latitudes. The $15 \mu \mathrm{m}$ brightness temperature map shows large-scale temperature gradients and planetary wave activity associated with the polar vortex. The limb-brightening effect is also visible, yield- ing increased brightness temperatures toward the scan edges. Gravity waves are hardly visible in the raw $15 \mu \mathrm{m}$ brightness temperature map but are isolated by means of the detrending method. The $15 \mu \mathrm{m}$ brightness temperature perturbation map reveals gravity wave activity over the southern Andes as well as the Transantarctic Mountains and Mac. Robertson Land. Previous climatological studies using AIRS data showed that these regions are in fact hot spots of stratospheric gravity wave activity (Gong et al., 2012; Hoffmann et al., 2013, 2016a). AIRS measurements in the spectral window region at $8.1 \mu \mathrm{m}$ can be used to detect storm systems (Aumann et al., 2006; Hoffmann and Alexander, 2010). The $8.1 \mu \mathrm{m}$ brightness temperature map indicates several intense storm systems over the southern oceans, with cloud top temperatures as low as $210-230 \mathrm{~K}$. However, the $15 \mu \mathrm{m}$ brightness temperature map shows that these storm systems do not cause any direct radiance signals in the stratospheric channels. Note that this only applies for mid- and high latitudes. At low latitudes, the tropopause is higher and clouds can reach the altitude range covered by the selected channels. Our data should not be used at low latitudes.

Figure 4 also shows detrended and noise-corrected $15 \mu \mathrm{m}$ brightness temperature variances on a $4^{\circ} \times 2^{\circ}$ longitude- 

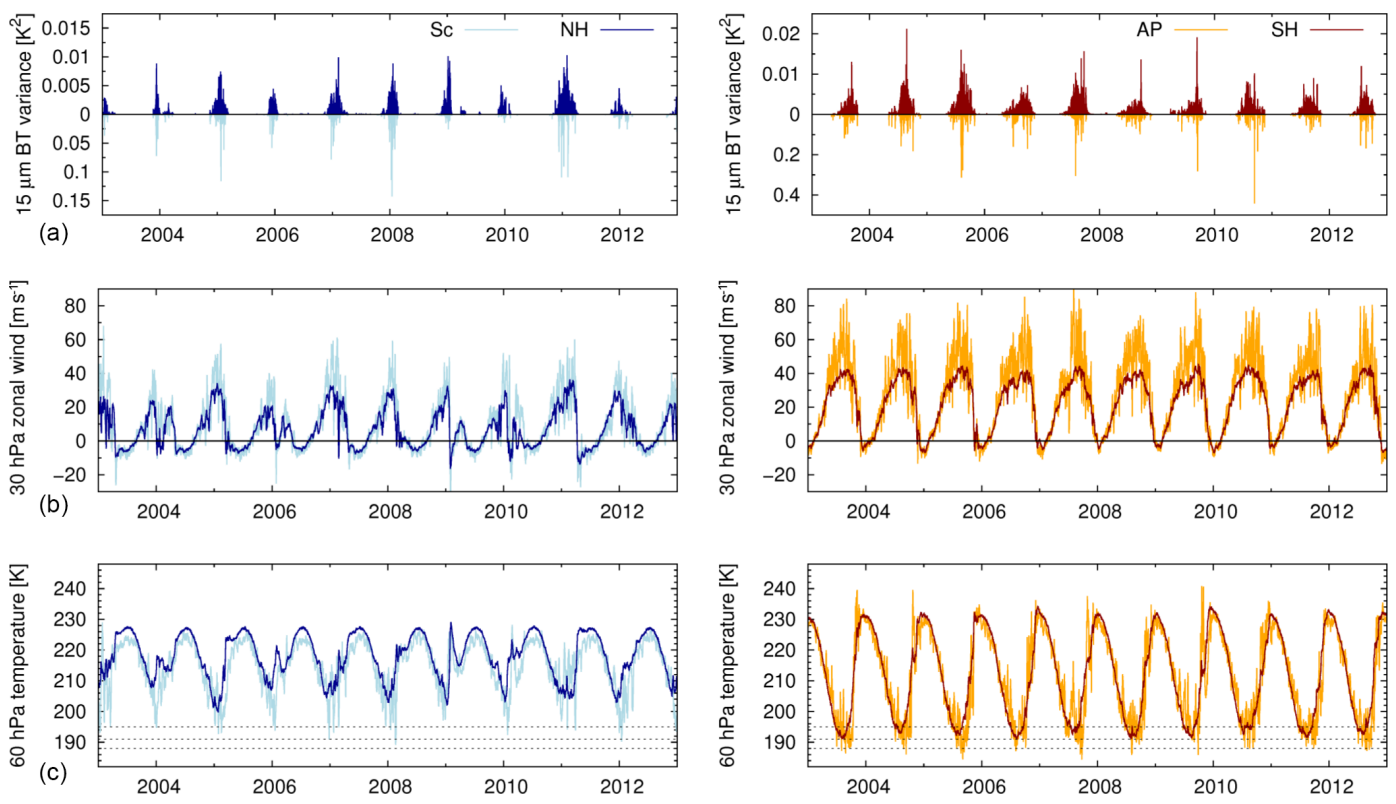

Figure 5. Time series of daily AIRS $15 \mu \mathrm{m}$ brightness temperature variances (top) as well as 6-hour ERA-Interim $30 \mathrm{hPa}$ zonal winds (middle) and $60 \mathrm{hPa}$ temperatures (bottom) at Northern Hemisphere mid- and high latitudes (NH; 55-85 ${ }^{\circ} \mathrm{N}$ ), the Scandinavian Mountains

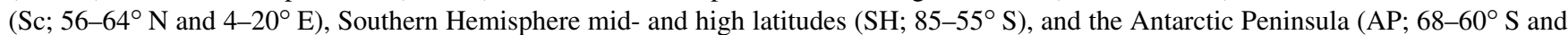
$\left.68-52^{\circ} \mathrm{W}\right)$. The dotted lines indicate typical PSC existence temperatures of $T_{\text {ice }}=188 \mathrm{~K}, T_{\mathrm{STS}}=191 \mathrm{~K}$, and $T_{\mathrm{NAT}}=195 \mathrm{~K}$ at $20 \mathrm{~km}$ of altitude (Pawson et al., 1995).

latitude grid calculated from the brightness temperature perturbations. Although AIRS already provides about $80 \%$ global coverage during $12 \mathrm{~h}$ time intervals, we decided to combine data over a $24 \mathrm{~h}$ time window to close data gaps and homogenize temporal coverage. The $4^{\circ} \times 2^{\circ}$ grid boxes typically contain $160-520$ footprints at mid- and high latitudes, which allows us to calculate variances with small sampling errors. Although AIRS provides measurement coverage up to the poles, any data beyond $\pm 85^{\circ}$ of latitude are excluded in this analysis. This is simply because the sampling coverage on a longitude-latitude grid decreases rapidly towards the poles. This could be mitigated by changing to another sampling grid, but we did not find this to be important because gravity wave activity beyond $\pm 85^{\circ}$ of latitude is usually rather low in the AIRS observations. Figure 4 shows that the variance map captures the individual gravity wave events found in the perturbation map. It also reveals that the noise correction very effectively suppresses noise signals in the variances. The map plot suggests that gravity wave signals can be reliably detected for variances as low as $5 \times 10^{-3} \mathrm{~K}^{2}$. Variances below this threshold can be affected by sampling errors. Note that based on an estimated $2 \%$ uncertainty of the noise correction, the corresponding uncertainty of the variances is in the range of $2.4 \times 10^{-4} \mathrm{~K}^{2}$ at a $250 \mathrm{~K}$ scene temperature to $7.8 \times 10^{-4} \mathrm{~K}^{2}$ at a $195 \mathrm{~K}$ scene temperature, which is well below the sampling error. We calculated the gridded $15 \mu \mathrm{m}$ brightness temperature variances on the $4^{\circ} \times 2^{\circ}$ grid on a daily basis for the entire 2003-2012 time period for further analyses.

\section{Temporal and spatial patterns of gravity wave activity}

In this section, we discuss the spatial and temporal patterns of the gravity wave activity in the lower stratosphere at midand high latitudes as observed by AIRS from 2003 to 2012. First, we focus on daily variations. Figure 5 shows time series of detrended and noise-corrected $15 \mu \mathrm{m}$ brightness temperature variances integrated from $85-55^{\circ} \mathrm{S}$ and $55-85^{\circ} \mathrm{N}$, respectively. As gravity wave activity typically occurs rather locally (cf. Fig. 4), the variances calculated for such large regions decrease to low levels. Maxima in different years range from $4.6 \times 10^{-3}$ to $1.0 \times 10^{-2} \mathrm{~K}^{2}$ in the Northern Hemisphere and $7.2 \times 10^{-3}$ to $2.1 \times 10^{-2} \mathrm{~K}^{2}$ in the Southern Hemisphere. However, note that these values are still considerably larger than the uncertainties of the noise correction. Figure 5 reveals that the daily variations in the gravity wave activity are substantial. Nevertheless, after detrending the daily time series with a 30-day running mean, the mean autocorrelation for a time lag of 1 day is 0.63 in the Northern Hemisphere and 0.57 in the Southern Hemisphere. The interannual variation of the autocorrelation is \pm 0.16 in the Northern Hemisphere and \pm 0.14 in the Southern Hemisphere. Despite the variability of the time series, this indicates that there is some persistence of gravity wave activity, which we attribute to 

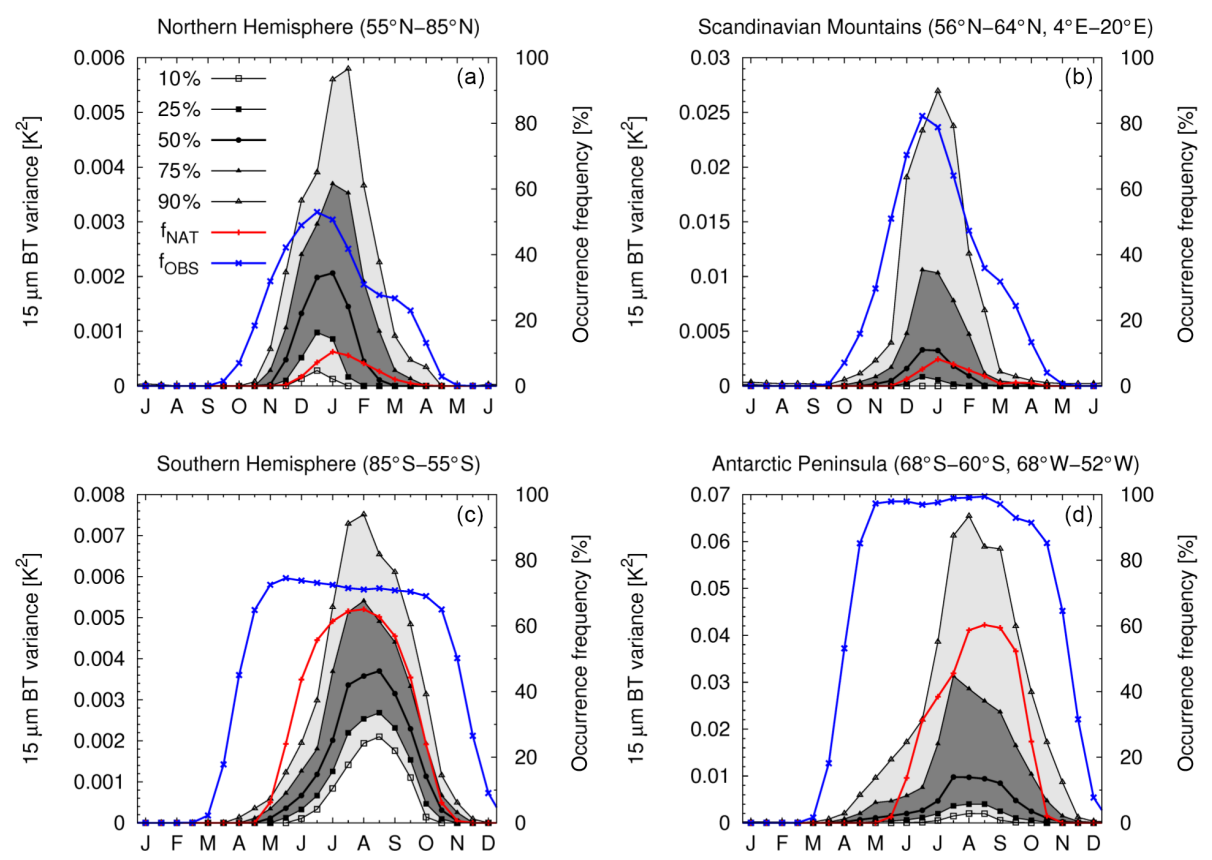

Figure 6. Seasonal cycle of gravity wave activity at northern (top left) and southern (bottom left) mid- and high latitudes as well as the Scandinavian Mountains (top right) and the Antarctic Peninsula (bottom right) from AIRS observations from 2003 to 2012 . The gravity wave activity within 30-day time windows is measured in terms of 10, 25, 50, 75, and $90 \%$ quantiles of $15 \mu \mathrm{m}$ brightness temperature variances. The red curves show the occurrence frequencies $f_{\text {NAT }}$ of ERA-Interim $60 \mathrm{hPa}$ temperatures falling below $T_{\text {NAT }}$. The blue curves show the occurrence frequencies $f_{\text {OBS }}$ of $30 \mathrm{hPa}$ zonal winds exceeding a threshold of $20 \mathrm{~m} \mathrm{~s}^{-1}$. Please note the different scales on the $y$ axes.

the persistence of both the gravity wave sources and the tropospheric and stratospheric background winds. Another remarkable feature of the time series displayed in Fig. 5 are the sudden stratospheric warmings, most notably the Northern Hemisphere major warming in January 2009. It is associated with a reversal of ERA-Interim $30 \mathrm{hPa}$ zonal winds from +30 to $-15 \mathrm{~m} \mathrm{~s}^{-1}$, an increase of $60 \mathrm{hPa}$ temperatures from 200 to $230 \mathrm{~K}$, and a decrease of observed gravity wave activity to almost zero.

The time series for both the Northern and Southern Hemisphere in Fig. 5 show a distinct seasonal cycle of gravity wave activity with maxima in the winter months. Gravity wave activity is typically stronger and lasts longer in the Southern Hemisphere, whereas the interannual variability and the intraseasonal variations are larger in the Northern Hemisphere. A statistical analysis of the seasonal cycle of gravity wave activity is presented in Fig. 6. We calculated the $10,25,50,75$, and $90 \%$ quantiles of the $15 \mu \mathrm{m}$ brightness temperature variance distributions for 30-day time windows. The analysis was performed with the time windows centered around the beginning or the middle of each month. Based on the 10 and $90 \%$ quantiles, we found that the seasonal cycle of gravity wave activity in the Northern Hemisphere typically begins in November and ends sometime between February and April. The cycle lasts about 2-6 months. Maximum activity occurs in January. In the Southern Hemisphere, the cy- cle begins between April and June and ends in November or December. The cycle lasts about 5-9 months. Maximum activity occurs in August. Figure 6 also shows the occurrence frequencies $f_{\mathrm{NAT}}$ of ERA-Interim $60 \mathrm{hPa}$ temperatures falling below $T_{\mathrm{NAT}}=195 \mathrm{~K}$. This allows us to compare the typical timing of synoptic-scale PSC occurrence to the timing of gravity wave activity. In the Southern Hemisphere, the seasonal cycle of gravity wave activity lasts slightly longer than the cycle of PSC activity, suggesting that wave-induced PSC formation is particularly important in fall and spring. The Arctic polar vortex is considerably warmer than the Antarctic polar vortex, and gravity waves may be an even more important source of PSCs in this case. We found values of $f_{\text {NAT }}$ of up to $10 \%$ for the Northern Hemisphere and up to $65 \%$ for the Southern Hemisphere. Furthermore, Fig. 6 also shows the occurrence frequencies $f_{\mathrm{OBS}}$ of ERA-Interim $30 \mathrm{hPa}$ zonal winds exceeding a threshold of $20 \mathrm{~m} \mathrm{~s}^{-1}$. This is a proxy for conditions that are linked to unidirectional and strongly increasing winds with height, which is a requirement for the occurrence of gravity waves with long vertical wavelengths that are best visible to AIRS. From $f_{\text {OBS }}$ we can infer a time window in which the atmospheric conditions are most suitable for AIRS to detect gravity waves. This time window is significantly longer than the window of synoptic-scale PSC activity. 
$\mathrm{NH}$ gravity waves | November

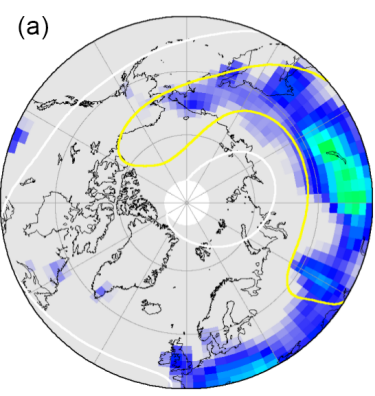

$\mathrm{NH}$ gravity waves | December

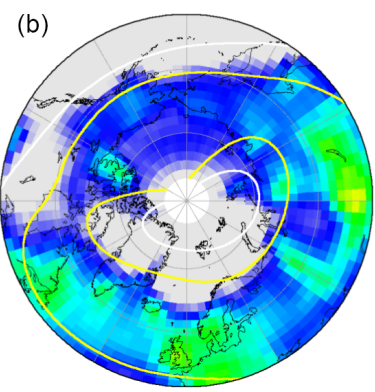

$\mathrm{NH}$ gravity waves | January

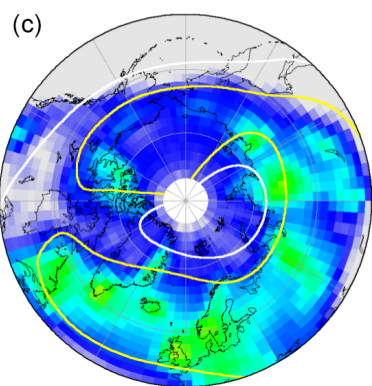

$\mathrm{NH}$ gravity waves | February

(d)

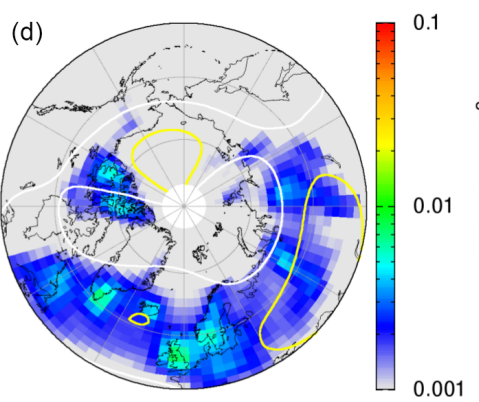

$\mathrm{NH}$ terrain

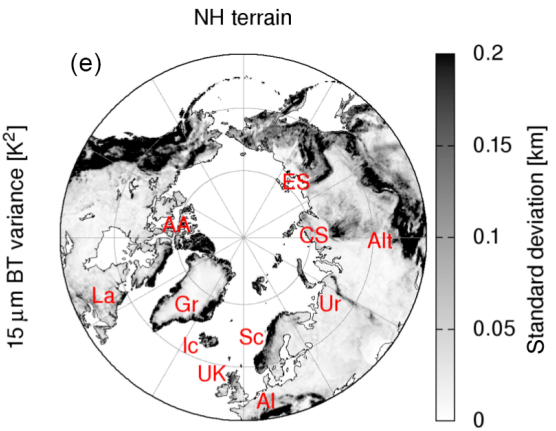

Figure 7. AIRS 2003-2012 monthly mean $15 \mu \mathrm{m}$ brightness temperature variances from November to March in the Northern Hemisphere. The contour lines show $30 \mathrm{hPa}$ ERA-Interim zonal winds at levels of $10 \mathrm{~m} \mathrm{~s}^{-1}$ (white), $20 \mathrm{~m} \mathrm{~s}^{-1}$ (yellow), $40 \mathrm{~m} \mathrm{~s}^{-1}$ (orange), and $60 \mathrm{~m} \mathrm{~s}^{-1}$ (red). The terrain height standard deviations on a $0.25^{\circ} \times 0.25^{\circ}$ horizontal grid (bottom, right) indicate the source regions of mountain waves. The red labels in the terrain map indicate the locations of the Arctic Archipelago (AA), Labrador (La), Greenland (Gr), Iceland (Ic), the United Kingdom (UK), the Scandinavian Mountains (Sc), the Alps (Al), the Ural Mountains (Ur), the Altai Mountains (Alt), the Central Siberian Plateau (CS), and the East Siberian Plateau (ES).

For comparison, we also analyzed the seasonal cycle for two orographic hot spots of gravity wave activity, the Scandinavian Mountains and the Antarctic Peninsula (Fig. 6). Local variances at the hot spots are much larger than the polar averages. For instance, the local maximum of the $90 \%$ quantile exceeds the polar average by a factor of 9 for the Antarctic Peninsula and by a factor of 4 for the Scandinavian Mountains. The variance distributions for the hot spots show positive skewness with a long tail towards large variances, as can be seen by comparing the ranges between the 10 and $90 \%$ quantiles and the median. This indicates that few mountain wave events contribute substantially to gravity wave activity at these hot spots, but they are strong. Figure 5 shows that both the $60 \mathrm{hPa}$ temperatures and $30 \mathrm{hPa}$ zonal winds vary much more locally at the hot spots compared with the polar regions as a whole, in particular in the Northern Hemisphere. The local variations of the zonal wind increase the chances of AIRS gravity wave observations at the hot spots compared with the polar regions. The maximum of $f_{\text {OBS }}$ is close to $100 \%$ for the Antarctic Peninsula, $75 \%$ for the Southern Hemisphere, $82 \%$ for the Scandinavian Mountains, and $53 \%$ for the Northern Hemisphere. The maximum PSC occurrence frequencies $f_{\mathrm{NAT}}$ at the hot spots are only slightly lower (2-5 percentage points) than those for the polar regions. However, we note that the onset of synoptic-scale
PSC formation at the Antarctic Peninsula is in June, which is a month later compared with the Southern Hemisphere polar region. Gravity wave activity at the Antarctic Peninsula starts as early as April. This further stresses the important role of the Antarctic Peninsula for gravity-wave-induced PSC formation.

In order to analyze the spatial patterns and to identify source regions of gravity wave activity, we calculated monthly variances on the $4^{\circ} \times 2^{\circ}$ longitude-latitude grid directly from the daily data. In Figs. 7 and 8, we also show maps of terrain height standard deviations calculated from a 2 min gridded global relief data set (ETOPO2v2; National Geophysical Data Center, 2006) to indicate possible orographic sources of gravity wave activity. The AIRS maps indicate that gravity wave activity increases significantly at a number of orographic hot spots. In the Northern Hemisphere, this includes (from west to east) the Arctic Archipelago, Labrador, Greenland, Iceland, the United Kingdom, the Alps, the Scandinavian Mountains, the Ural Mountains, the Altai Mountains, the Central Siberian Plateau, and the East Siberian Plateau. Gravity wave activity over the Rocky Mountains is largely absent, which is due to relatively low stratospheric background winds over this mountain range (Hoffmann et al., 2013, 2014). In the Southern Hemisphere, we found increased gravity wave activity in 

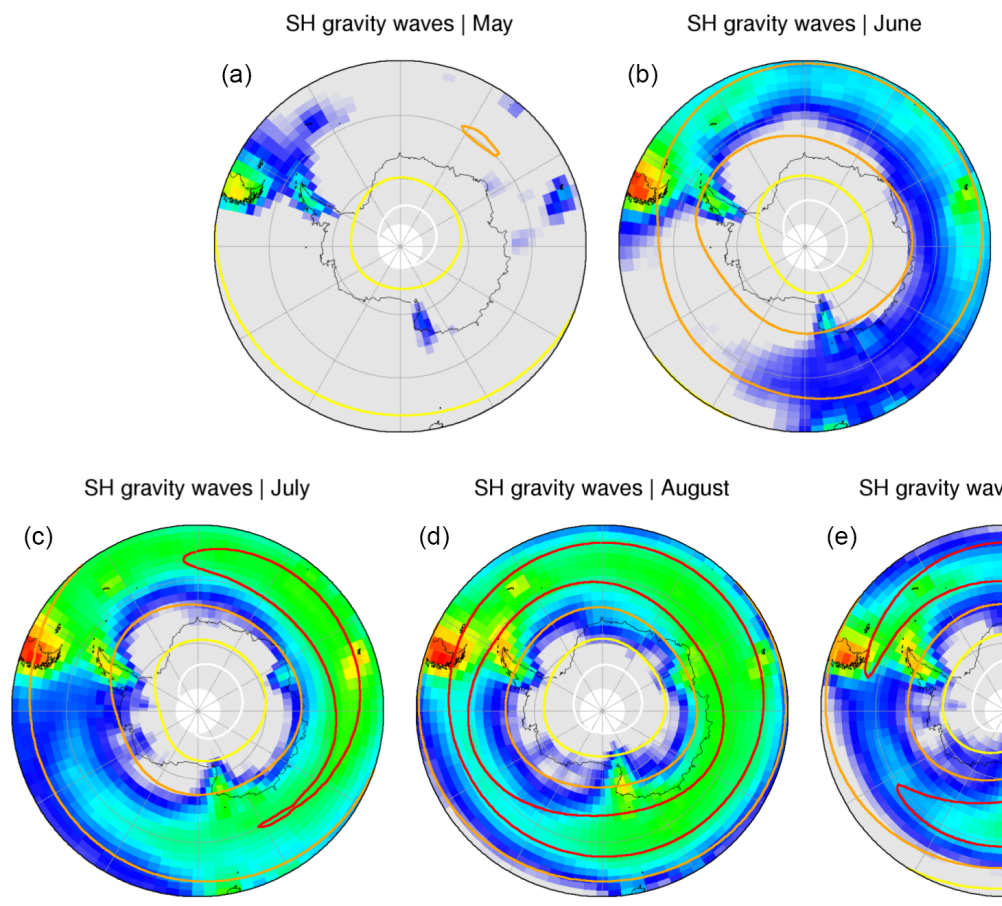

SH gravity waves | September
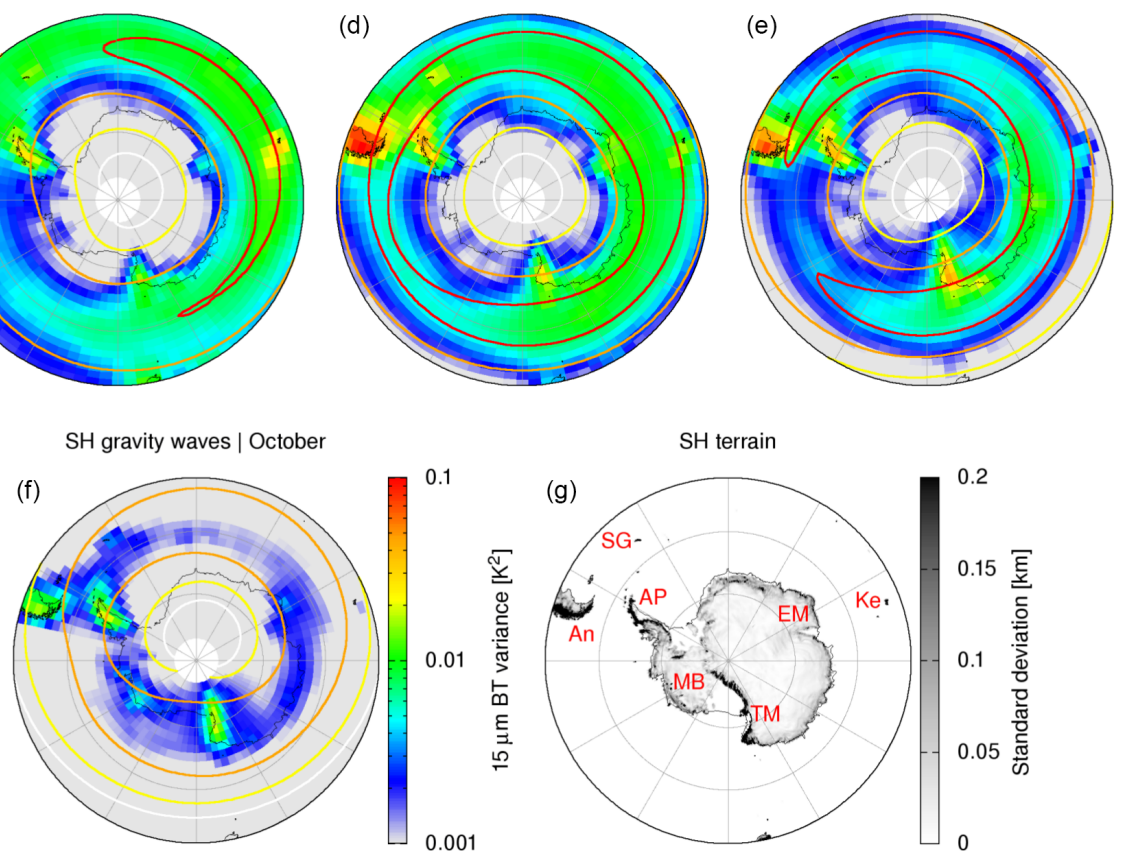

Figure 8. Same as Fig. 7, but for the Southern Hemisphere and the months of May to October. The red labels in the terrain map indicate the locations of Marie Byrd Land (MB), the Andes (An), the Antarctic Peninsula (AP), South Georgia (SG), Enderby Land and Mac. Robertson Land (EM), the Kerguelen Islands (Ke), and the Transantarctic Mountains (TM).

a latitude band around $70-50^{\circ} \mathrm{S}$ during the winter months, which is attributed mostly to jet and storm sources (Sato et al., 2012; Hendricks et al., 2014; Hindley et al., 2015). Orographic hot spots can be identified in the southern Andes, the Antarctic Peninsula, South Georgia, the Kerguelen Islands, and the Transantarctic Mountains. As there is large variability of gravity wave activity, in particular in the Northern Hemisphere, we calculated standard errors of the monthly means shown in Figs. 7 and 8 to assess whether they are representative. We found standard errors of $29-39 \%$ for November to February for the Northern Hemisphere and 18$21 \%$ for May to October for the Southern Hemisphere. The spatial patterns of gravity wave activity in the lower stratosphere found here agree well with those identified by Gong et al. (2012) and Hoffmann et al. (2013, 2014, 2016a) for the mid- and upper stratosphere.
Strong background winds in the stratosphere tend to go along with unidirectional and increasing winds with height (Orr et al., 2010). In this case, wave refraction will result in long vertical wavelengths (Wu and Eckermann, 2008), which are best visible to AIRS. Conversely, weak background winds are associated with gravity waves with short vertical wavelengths, which are generally not detectable by AIRS. This combined effect of the stratospheric background winds and the vertical wavelength sensitivity of AIRS is referred to as an "observational filter" (Alexander and Barnet, 2007; Hoffmann et al., 2014, 2016a). Figures 7 and 8 also show the contours of ERA-Interim monthly mean zonal winds at $30 \mathrm{hPa}$. The $30 \mathrm{hPa}$ level (about $25 \mathrm{~km}$ altitude) is close to the altitude range where the AIRS observations provide maximum sensitivity to stratospheric temperatures. Figures 7 and 8 indicate that the $30 \mathrm{hPa}$ zonal winds have a sig- 
nificant influence on the observability of gravity waves with AIRS. For both the Northern and Southern Hemisphere, we found that strong westerlies are a prerequisite for the observation of gravity wave activity with AIRS. The comparison suggests that zonal winds need to exceed levels of about 10$20 \mathrm{~m} \mathrm{~s}^{-1}$ before gravity wave activity becomes visible in the AIRS data. This shows that the observational filter needs to be taken into account in the analysis of AIRS gravity wave observations.

\section{Evaluation of temperature fluctuations in the ECMWF operational analysis}

In this study, we used the new AIRS data set to evaluate explicitly resolved temperature fluctuations due to gravity waves in the ECMWF operational analysis. During the time period considered here (2003-2012), the horizontal resolution of the ECMWF operational analysis was increased from T511 (39 km effective resolution) to T1279 $(16 \mathrm{~km})$, the number of model levels was increased from 60 to 91 , and the model top was raised from 0.1 to $0.01 \mathrm{hPa}$. The typical vertical resolution is about $0.5-1.1 \mathrm{~km}$ at $15-30 \mathrm{~km}$ of altitude. We considered analysis data at 00:00 and 12:00 UTC and forecast data at 03:00, 06:00, 09:00, 15:00, 18:00, and 21:00 UTC. AIRS radiance data have been used for operational forecasting since October 2003 (McNally et al., 2006; Dee et al., 2011). Observations of up to 210 channels are used in the assimilation procedure, of which 10 are also considered in our AIRS data product. The comparisons of AIRS and ECMWF data presented here are therefore not strictly based on independent data and should be considered as an evaluation rather than a validation. However, the assimilation of AIRS data at ECMWF is restricted to cloud-free scenes, and an additional random thinning operation is applied to ensure a minimum horizontal spacing of $120 \mathrm{~km}$ between the footprints. This poses a Nyquist limit of $240 \mathrm{~km}$ on horizontal wavelengths regarding the direct assimilation of small-scale gravity waves from AIRS observations for the analysis. Wave patterns with shorter horizontal wavelengths are most likely generated by the model itself.

In our comparison, we took the effects of radiative transfer and the AIRS satellite observation geometry into account. First, we extracted temperature profiles from the ECMWF data at the locations of individual satellite footprints by means of 3-D linear interpolation. Next, we convolved the temperature profiles with the weighting function of the selected channels. This gave us simulated brightness temperature measurements on the AIRS measurement grid. Gravity wave signals were then extracted by means of the same detrending procedure as used for the real AIRS data. The main difficulty in this comparison is related to the coarse time resolution $(3 \mathrm{~h})$ at which the ECMWF data are provided. We tested different interpolation schemes (nearest neighbor, linear, and cubic) but found that temporal interpolation often does not provide physically meaningful solutions for gravity waves that may propagate through the troposphere and stratosphere within just a few hours. Therefore, we decided to avoid time interpolation altogether and to perform the analysis directly with the meteorological data at the $3 \mathrm{~h}$ synoptic time steps. Daily gravity wave variances were calculated using the data of all synoptic time steps on each day. This approach introduces some uncertainty in the analysis, but it was still found to provide the best overall agreement with real AIRS observations.

As an example, Fig. 9 shows a qualitative comparison of $15 \mu \mathrm{m}$ brightness temperature perturbations from real AIRS measurements and corresponding simulated measurements based on the ECMWF operational analysis data. The real measurements shown here were obtained on 11 December 2003 from 12:00 to 24:00 UTC in the Northern Hemisphere and on 22 July 2011 from 00:00 to 12:00 UTC in the Southern Hemisphere. The simulated measurements apply to 18:00 and 06:00 UTC in synoptic time on these days, respectively. The AIRS measurements in the Northern Hemisphere show mountain waves near the east coast of Greenland as well as the Scandinavian Mountains. There is also a band of wave activity around $60-75^{\circ} \mathrm{N}$ extending over large parts of Asia. The wave activity in this region can be attributed not only to orography, but also to jet and storm sources. The example for the Southern Hemisphere shows strong mountain waves at the southern Andes. The measurements also reveal non-orographic wave activity related to jet and storm sources at $50-70^{\circ} \mathrm{S}$ and $60-120^{\circ} \mathrm{E}$, which is possibly mixed with orographic waves near coastal East Antarctica. The qualitative comparison shows that both orographic and non-orographic waves are captured by the ECMWF operational analysis to a great extent; i.e., there is remarkably good agreement between the regions where gravity waves were represented in the analysis and where they actually occurred. Despite the time differences, even the details of the wave patterns look similar, in particular for the Southern Hemisphere example in July 2011. The improved horizontal resolution of the ECMWF operational analysis is likely the reason that individual patterns are better captured in the Southern Hemisphere example for the year 2011 compared to the Northern Hemisphere example for the year 2003. However, we note that the wave amplitudes from the simulations are lower than the wave amplitudes from the AIRS measurements in both examples.

To quantify the systematic differences between the wave amplitudes in the AIRS observations and the meteorological analyses, we analyzed seasonal peak events. We selected the day with the largest gravity wave variance from the AIRS time series (Fig. 5) for each winter season in the Northern and Southern Hemisphere. Figure 10 shows a bar chart of $15 \mu \mathrm{m}$ brightness temperature standard deviations for these peak events calculated from the detrended and noisecorrected $15 \mu \mathrm{m}$ brightness temperature variances shown in Fig. 5. Here, we present standard deviations rather than vari- 

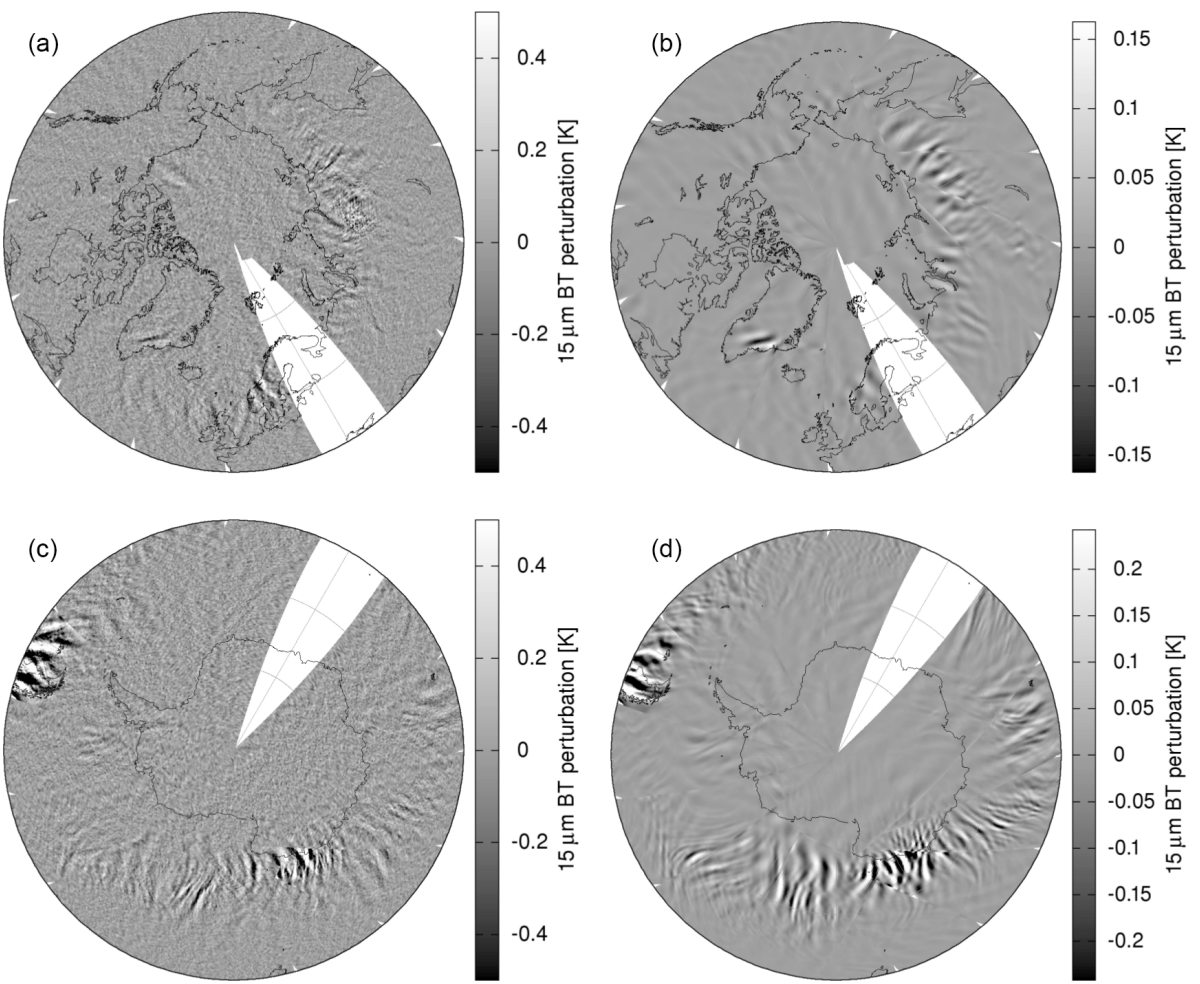

Figure 9. AIRS measurements of $15 \mu \mathrm{m}$ brightness temperature perturbations (left) and corresponding simulations based on ECMWF operational analysis temperatures (right). Real measurements took place on 11 December 2003 from 12:00 to 24:00 UTC in the Northern Hemisphere (top) and on 22 July 2011 from 00:00 to 12:00 UTC in the Southern Hemisphere (bottom). Simulated measurements are based on synoptic data at 18:00 and 06:00 UTC, respectively. The color bar ranges are scaled individually for better comparisons of the wave patterns.
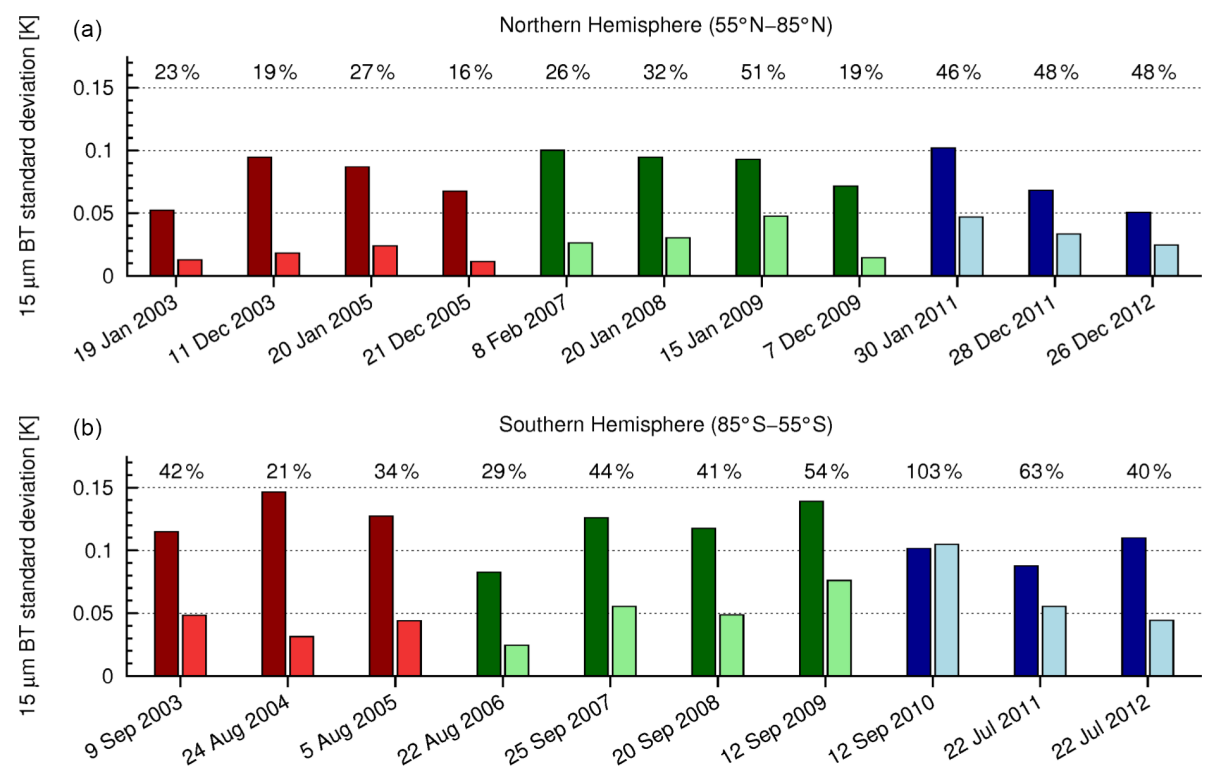

Figure 10. Peak events of gravity wave activity in individual 2003-2012 Northern and Southern Hemisphere winter seasons. The $15 \mu \mathrm{m}$ brightness temperature standard deviations were inferred from real AIRS measurements (dark shading) or simulations based on ECMWF operational analysis data (light shading). The color coding refers to the resolution of the ECMWF data (red is T511L60, green is T799L91, and blue is T1279L91). The percentages at the top of the plots indicate the relative differences of the simulated data with respect to the measurements. 
ances, because those can be related more directly to gravity wave amplitudes. Figure 10 shows that the simulated wave amplitudes almost always underestimate the observed wave amplitudes. On average, the ECMWF operational analysis reproduces $32 \pm 13 \%$ of the observed standard deviations in the Northern Hemisphere and $47 \pm 22 \%$ in the Southern Hemisphere. Commonly, gravity wave amplitudes are better reproduced in the Southern Hemisphere than in the Northern Hemisphere. This difference between the hemispheres is related to differences in the typical gravity wave spectra in both hemispheres. For the 21 peak events analyzed here, a 2-D spectral analysis of the AIRS data using the S-transform method (Stockwell et al., 1996; Alexander and Barnet, 2007) yielded mean horizontal wavelengths of $116 \pm 52 \mathrm{~km}$ in the Northern Hemisphere and $133 \pm 72 \mathrm{~km}$ in the Southern Hemisphere. These differences might be due to the gravity wave sources, such as orography, convection, and jets, as well as differences in the background flow between the hemispheres. The model produces shorter horizontal wavelengths in the Northern Hemisphere; however, the wavelengths were overall longer than AIRS, and we found stronger attenuation of the wave amplitudes in the model. We attribute the interannual variability of the scaling factors of the wave amplitudes between the AIRS and ECMWF data to atmospheric variability, but also to improvements in the spatial resolution, the forecast model, and the data assimilation system of the operational analysis over time.

\section{A survey of gravity-wave-induced PSC formation events}

In this section, we present a survey of joint AIRS gravity wave and Envisat MIPAS PSC observations from 2003 to 2012. Like Aqua, Envisat operated in a nearly polar, low earth orbit $\left(790 \mathrm{~km}\right.$ of altitude, $98^{\circ}$ of inclination, $101 \mathrm{~min}$ orbital period) with Equator crossings at 10:00 and 22:00 LT. Envisat MIPAS (Fischer et al., 2008) measured the 4.15$14.6 \mu \mathrm{m}$ limb emission spectra of atmospheric constituents from the mid-troposphere to the mesosphere at high spectral resolution. Nominal measurements in the "full resolution" phase $\left(0.025 \mathrm{~cm}^{-1}\right.$ of spectral resolution) from 2002 to 2004 provided a $550 \mathrm{~km}$ horizontal sampling and a $3 \mathrm{~km}$ vertical sampling in the lower stratosphere. This was improved to $410 \mathrm{~km}$ and $1.5-2 \mathrm{~km}$ in the "optimized resolution" phase $\left(0.0625 \mathrm{~cm}^{-1}\right)$ from 2005 to 2012 . The instantaneous field of view of MIPAS covers 3-4 km (elevation) $\times 30 \mathrm{~km}$ (azimuth). Several studies have demonstrated that MIPAS was capable of detecting PSCs based on specific spectral signatures in the mid-infrared (Spang et al., 2004, 2005; Höpfner et al., 2006a, b; Spang et al., 2012). A particular advantage of MIPAS was its sensitivity to low particle concentrations due to the long integration paths of the limb observation geometry. Here, we make use of a new MIPAS PSC data product introduced by Spang et al. (2016), which uses radiance mea- surements at 7.1, 8.2, 10.5, 12.0, and $12.7 \mu \mathrm{m}$ to detect PSCs and to classify different particle types. The new method has been developed and tested with a database of radiative transfer model calculations of realistic PSC particle size distributions, geometries, and composition. The detection and classification results were compared with space-borne lidar observations. Spang et al. (2016) showed that ice particles are classified most accurately with the new method.

Our survey of gravity-wave-induced PSC formation events is based on daily maps of detrended and noise-corrected AIRS $15 \mu \mathrm{m}$ brightness temperature variances and MIPAS PSC detections. Selected examples of these maps are shown in Fig. 11. MIPAS PSC detections are shown for the altitude range of about $18-22 \mathrm{~km}$ (450-550 K potential temperature), which coincides with the range of polar vortex temperature minima (Randel et al., 2004) and PSC occurrence frequency maxima (Poole and Pitts, 1994; Spang et al., 2005; Pitts et al., 2009) during the course of the polar winter. To help link the PSC observations to gravity wave activity, further information was added to the maps following Spang et al. (2016). PSC existence temperatures were estimated following Hanson and Mauersberger (1988) and Marti and Mauersberger (1993) based on ERA-Interim pressure and temperature data at the $500 \mathrm{~K}$ isentropic level as well as typical stratospheric values for $\mathrm{HNO}_{3}$ (9 ppbv) and $\mathrm{H}_{2} \mathrm{O}(4 \mathrm{ppmv})$. PSC detections associated with synoptic-scale temperatures significantly larger than the specific existence temperature are candidates for gravity-wave-induced formation events. Furthermore, the maps include contours of the Montgomery streamfunction (calculated from ERA-Interim data), representing streamlines of the geostrophic wind at the $500 \mathrm{~K}$ isentropic level. The streamfunctions illustrate the flow of air masses on short time scales and can be used to infer whether the MIPAS PSC detections occurred downstream of AIRS gravity wave observations. Alexander et al. $(2011,2013)$ already highlighted the importance of the advection of PSCs away from the regions where temperature perturbations were observed. The streamfunction approach helps to overcome difficulties related to the mismatch in time between the Aqua and Envisat overpasses and the synoptic time steps of the meteorological data.

Figure 11 shows two examples of gravity-wave-induced PSC formation events in the Northern Hemisphere. On 25 January 2007, MIPAS detected ice PSCs over Scandinavia at synoptic-scale temperatures of up to 6-9 K above $T_{\text {ice. }}$. These detections are associated with weak gravity wave activity observed by AIRS over the Scandinavian Mountains. On 7 January 2011, MIPAS detected ice, STS, and NAT PSCs over the Arctic Archipelago at synoptic-scale temperatures of about $3 \mathrm{~K}$ above $T_{\mathrm{NAT}}$. Although the Arctic Archipelago was found to be a gravity wave hot spot in the Northern Hemisphere (Sect. 3), no indication of gravity wave activity is seen in this region on this particular day in the AIRS data. A reason might be that $30 \mathrm{hPa}$ horizontal wind speeds directly above the MIPAS detections are relatively 

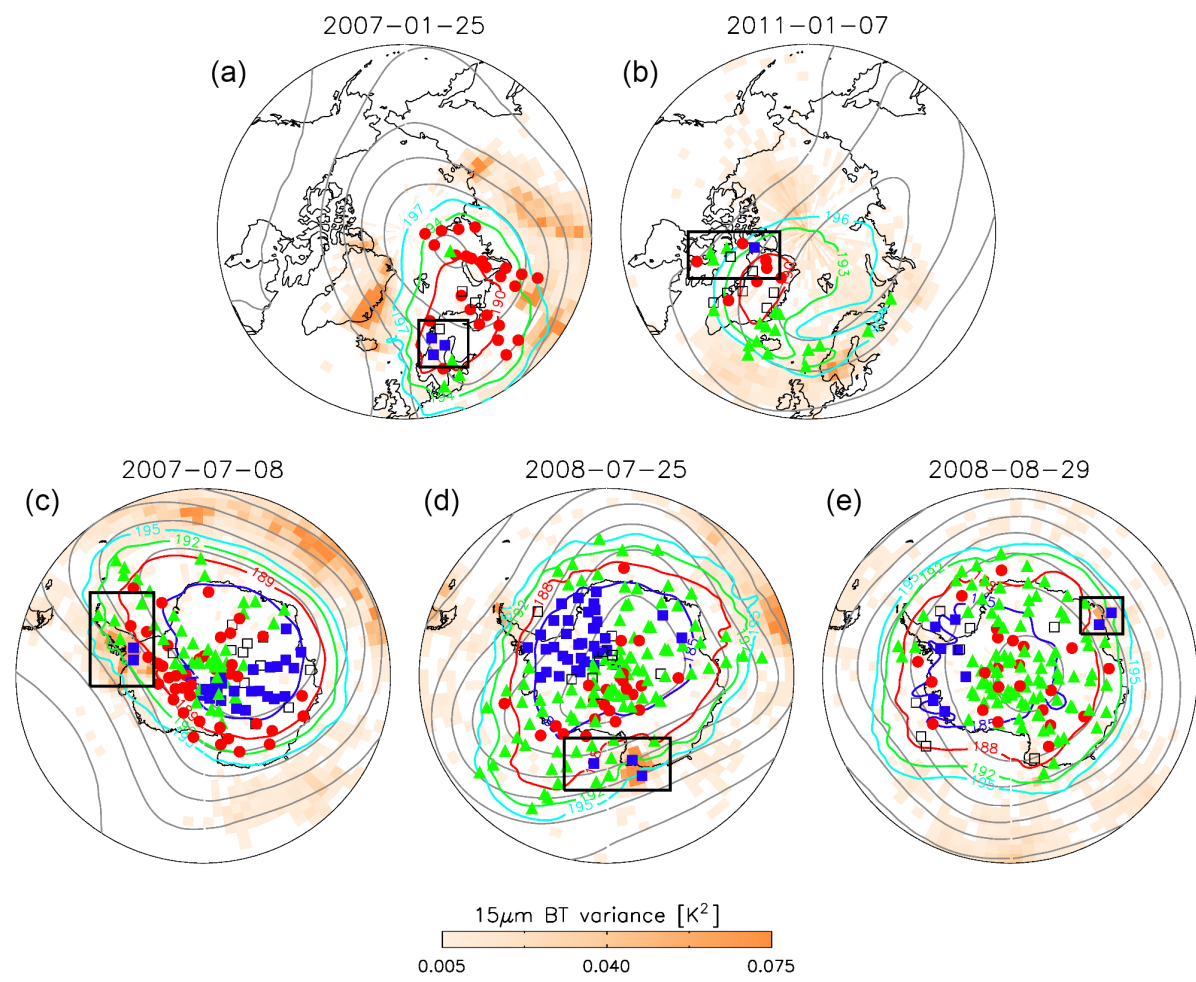

Figure 11. Examples of gravity-wave-induced PSC formation events in the Northern Hemisphere (top) and the Southern Hemisphere (bottom). Events are indicated by black boxes. The orange shading shows detrended and noise-corrected AIRS $15 \mu \mathrm{m}$ brightness temperature variances. The symbols show MIPAS PSC observations (ice is indicated by blue squares, STS by red circles, NAT by green triangles, and unclassified by black squares) at a potential temperature of $450-550 \mathrm{~K}$. The contour lines indicate PSC existence temperatures ( $T_{\text {ice }}$ is blue, $T_{\mathrm{STS}}$ is red, $T_{\mathrm{NAT}}$ is green, and $T_{\mathrm{NAT}}+3 \mathrm{~K}$ is cyan) and the Montgomery streamfunction (gray) at the $500 \mathrm{~K}$ isentropic level.

low (about 35-45 $\mathrm{m} \mathrm{s}^{-1}$ ) compared with the other cases studied. The AIRS observational filter causes stronger attenuation of the observed wave amplitudes in this case. Gravity wave activity is observed 3-6h upstream over the Beaufort Sea where horizontal wind speeds increase. Figure 11 also presents three examples of gravity-wave-induced PSC formation in the Southern Hemisphere. The measurements on 8 July 2007 show a rather typical example of the formation of ice PSCs due to mountain waves at the Antarctic Peninsula. The ice PSCs are formed at synoptic-scale temperatures of up to $4-10 \mathrm{~K}$ above $T_{\text {ice. }}$. NAT particles are observed further downstream of the Antarctic Peninsula, which is consistent with the ice particles serving as condensation nuclei for NAT formation (Carslaw et al., 1998a; Höpfner et al., 2006b; Eckermann et al., 2009). Although mountain wave activity is most frequent at the Antarctic Peninsula (Hoffmann et al., 2016a), other orographic features in Antarctica can also play a role in PSC formation. The AIRS and MIPAS observations on 25 July and 29 August 2008 show cases of the mountainwave-induced formation of ice PSCs over the Transantarctic Mountains and near Enderby Land and Mac. Robertson Land, respectively.

In Fig. 11, we displayed $15 \mu \mathrm{m}$ brightness temperature variances up to a level of $0.075 \mathrm{~K}^{2}$. A relatively low cut- off was selected here to also make weak wave signals visible. Following the approach of Alexander and Grimsdell (2013), we performed a cross-check for the orographic wave events to confirm that these are indeed cases with substantial true gravity wave amplitudes. We computed the vertical wavelength $\lambda_{z}$ from the gravity wave dispersion relation for stationary waves, assuming that the ground-based frequency and phase speed are zero:

$\lambda_{z}=2 \pi\left[\left(\frac{N}{u}\right)^{2}-\left(\frac{2 \pi}{\lambda_{x}}\right)^{2}\right]^{-0.5}$.

$N \approx 0.02 \mathrm{~s}^{-1}$ refers to the stratospheric buoyancy frequency. The background wind speed $u$ was taken from the ERAInterim reanalysis at $30 \mathrm{hPa}$. The horizontal wavelength $\lambda_{x}$ was determined by means of spectral analysis of the AIRS data. The vertical wavelength estimate $\lambda_{z}$ was used to determine the amplitude response $R$ from the data shown in Fig. 1 . Then, $R$ was used to estimate the true gravity wave amplitude $T^{\prime}$ from the measured brightness temperature amplitude $\mathrm{BT}^{\prime}$ according to $T^{\prime}=\mathrm{BT}^{\prime} R^{-1}$. The results of the calculations for the four orographic wave events in Fig. 11 are summarized in Table 2. Based on background wind speeds of about $55-65 \mathrm{~m} \mathrm{~s}^{-1}$ at $30 \mathrm{hPa}$ and horizontal wavelengths of 

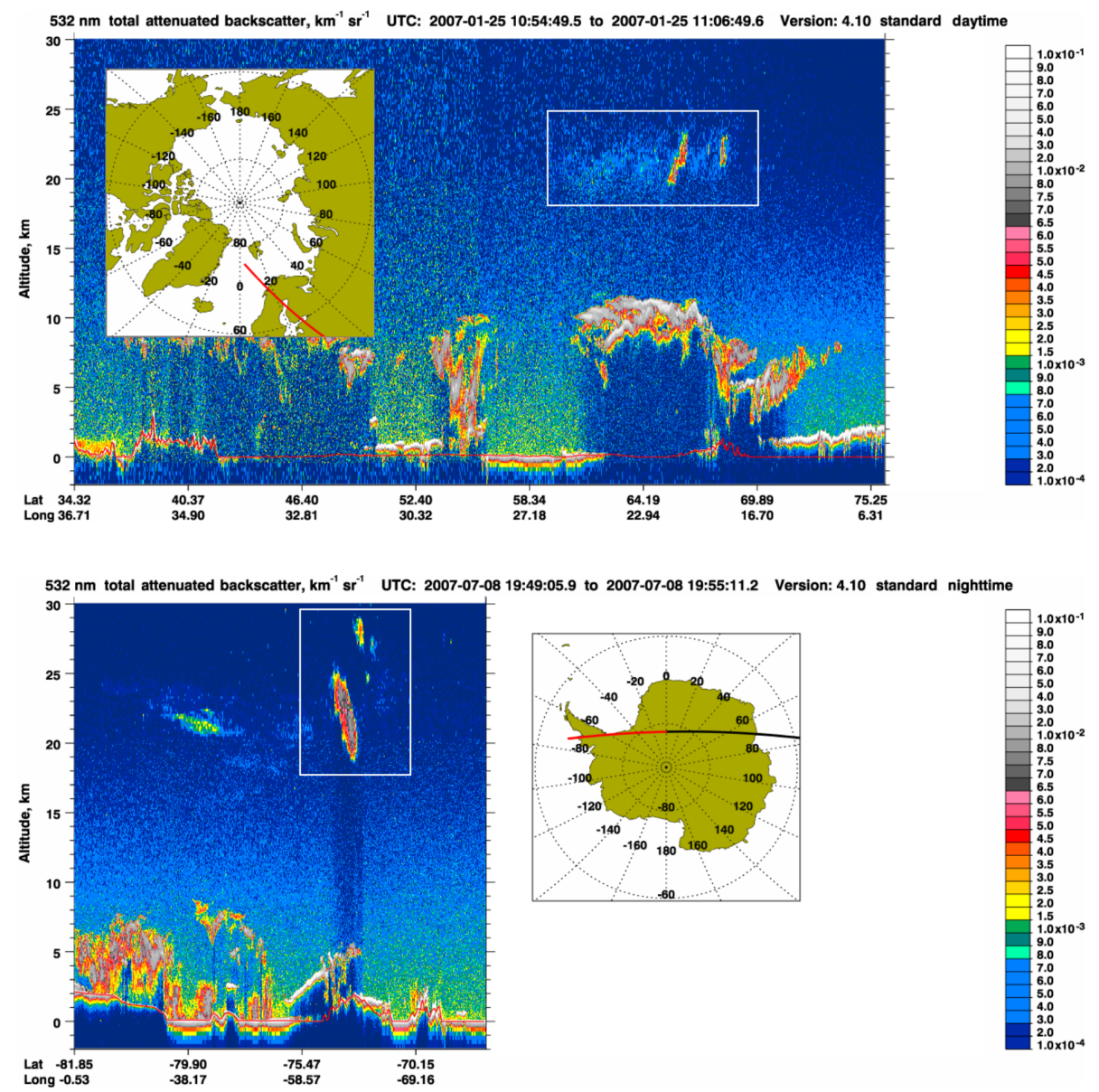

Figure 12. CALIOP browse images of $532 \mathrm{~nm}$ total attenuated backscatter for two of the case studies presented in Fig. 11. The inset maps show the satellite track, and the white boxes indicate the features associated with polar stratospheric clouds.

Table 2. Estimation of gravity wave amplitudes for the orographic events shown in Fig. 11.

\begin{tabular}{lrrrrrr}
\hline Event date & $\begin{array}{r}u \\
\left(\mathrm{~m} \mathrm{~s}^{-1}\right)\end{array}$ & $\begin{array}{r}\lambda_{x} \\
(\mathrm{~km})\end{array}$ & $\begin{array}{r}\lambda_{z} \\
(\mathrm{~km})\end{array}$ & $\begin{array}{r}R \\
(\%)\end{array}$ & $\begin{array}{r}\mathrm{BT}^{\prime} \\
(\mathrm{K})\end{array}$ & $\begin{array}{r}T^{\prime} \\
(\mathrm{K})\end{array}$ \\
\hline $2007-01-25$ & 65 & 113 & 20.7 & 21.6 & 1.8 & 8.3 \\
$2007-07-08$ & 55 & 111 & 17.5 & 15.4 & 1.4 & 9.1 \\
$2008-07-25$ & 65 & 128 & 20.7 & 21.6 & 2.6 & 12.0 \\
$2008-08-29$ & 60 & 95 & 19.2 & 18.5 & 1.3 & 7.0 \\
\hline
\end{tabular}

about $95-130 \mathrm{~km}$, we found vertical wavelengths of about $17-21 \mathrm{~km}$. The corresponding amplitude response is about 15-22\%. Brightness temperature amplitudes of about 1.3$2.6 \mathrm{~K}$ scale to true gravity wave amplitudes of about $7-12 \mathrm{~K}$. Such large true amplitudes are indeed consistent with observations of ice PSCs well above the frost point.

As another cross-check of the case studies shown in Fig. 11, we performed a comparison with PSC observations of the Cloud-Aerosol Lidar with Orthogonal Polarization (CALIOP) (Pitts et al., 2009; Winker et al., 2010) instru- ment. CALIOP is an active lidar instrument that probes the vertical and along-track structure of aerosols and clouds with unprecedented spatial resolution, i.e., $180 \mathrm{~m}$ in the vertical direction and $1.67 \mathrm{~km}$ in the along-track direction at 20.2$30.1 \mathrm{~km}$ of altitude. Figure 12 shows CALIOP observations for the events on 25 January 2007 in the Northern Hemisphere and 8 July 2007 in the Southern Hemisphere. The CALIOP browse images in Fig. 12 indicate the presence of PSCs in close proximity to MIPAS detections of ice PSCs at 20-23 and 19-29 km of altitude, respectively. The $532 \mathrm{~nm}$ total attenuated backscatter shows maximum signals up to $8 \times 10^{-3} \mathrm{~km}^{-1} \mathrm{sr}^{-1}$. These large signals are a strong indicator of the presence of wave-induced ice particles. Note that stratospheric features can also be found in CALIOP observations for the three case studies not shown here. However, we note that in these cases the backscatter signals are weaker and may be caused by other types of PSC particles.

We also conducted backward trajectory calculations to confirm that the MIPAS detections of ice PSC are not related to synoptic-scale temperatures falling below $T_{\text {ice}}$, which suggests that gravity waves play a role in PSC formation for 
Table 3. Northern Hemisphere gravity-wave-induced PSC formation events.

\begin{tabular}{ll|ll}
\hline Date & Source region & Date & Source region \\
\hline $2003-02-10$ & Ural Mountains & $2008-01-01$ & Iceland \\
$2005-01-27$ & Scandinavian Mountains & $2008-01-28$ & Iceland \\
$2005-02-16$ & Greenland & $2008-02-10$ & Iceland \\
$2005-02-18$ & Greenland & $2008-12-24$ & Iceland \\
$2006-01-19$ & United Kingdom & $2010-01-03$ & Greenland \\
$2006-12-26$ & Scandinavian Mountains & $2010-12-07$ & Greenland \\
$2007-01-25$ & Greenland & $2011-01-06$ & non-orographic \\
$2007-02-13$ & Labrador & $2011-01-29$ & East Siberian Plateau \\
$2007-12-21$ & Scandinavian Mountains & $2011-12-27$ & Scandinavian Mountains \\
& & $2011-12-29$ & United Kingdom \\
\hline
\end{tabular}

these events. The calculations were performed with the Lagrangian particle dispersion model introduced by Hoffmann et al. (2016b) using both the ERA-Interim and the ECMWF operational analysis as meteorological input data. The calculations cover a time period of $24 \mathrm{~h}$. We conducted the calculations for ensembles of 100 trajectories to take into account the broad measurement volume of MIPAS as well as atmospheric diffusion and subgrid-scale wind fluctuations. The results for two detections are presented in Fig. 13. We found that the mean temperatures of the air parcels are about 4-8 $\mathrm{K}$ above $T_{\text {ice }}$ at the beginning and rise by another 15$25 \mathrm{~K}$ towards the end of the simulations. This indicates that large-scale synoptic temperatures are likely not the reason for PSC formation. Furthermore, note that the temperature curve for the 25 January 2007 case study shows a wave-like signature with about 4-5 K of amplitude for the operational analysis and $1-2 \mathrm{~K}$ for the ERA-Interim during the first $3 \mathrm{~h}$ of the simulations. Considering the wave perturbations, the local temperature is close to $T_{\text {ice }}$ for the operational analysis. This provides more evidence that mountain waves over Scandinavia play an important role in PSC formation in this case. For all the cases presented in Fig. 11, we analyzed trajectory calculations for 22 MIPAS detections of ice PSCs that occurred above $T_{\text {ice }}$, but we did not find a case in which the temperatures along the trajectories dropped below $T_{\text {ice }}$ for an extended period of time.

Based on the daily maps, we performed a survey of all AIRS and MIPAS observations in the northern and southern polar winter seasons from 2003 to 2012. In this survey, we identified 48 events of gravity-wave-induced PSC formation (Tables 3 and 4) with 29 events located in the Southern Hemisphere and 19 events located in the Northern Hemisphere. This first survey suggests that formation events appear more frequently in the Southern Hemisphere than in the Northern Hemisphere. This is not consistent with studies showing that there are larger proportions of PSCs due to orographic gravity waves in the Arctic than in the Antarctic (Kohma and Sato, 2011; Alexander et al., 2013). However, our findings might be biased due to the more stable atmospheric conditions in the Southern Hemisphere, which ease the identifica-
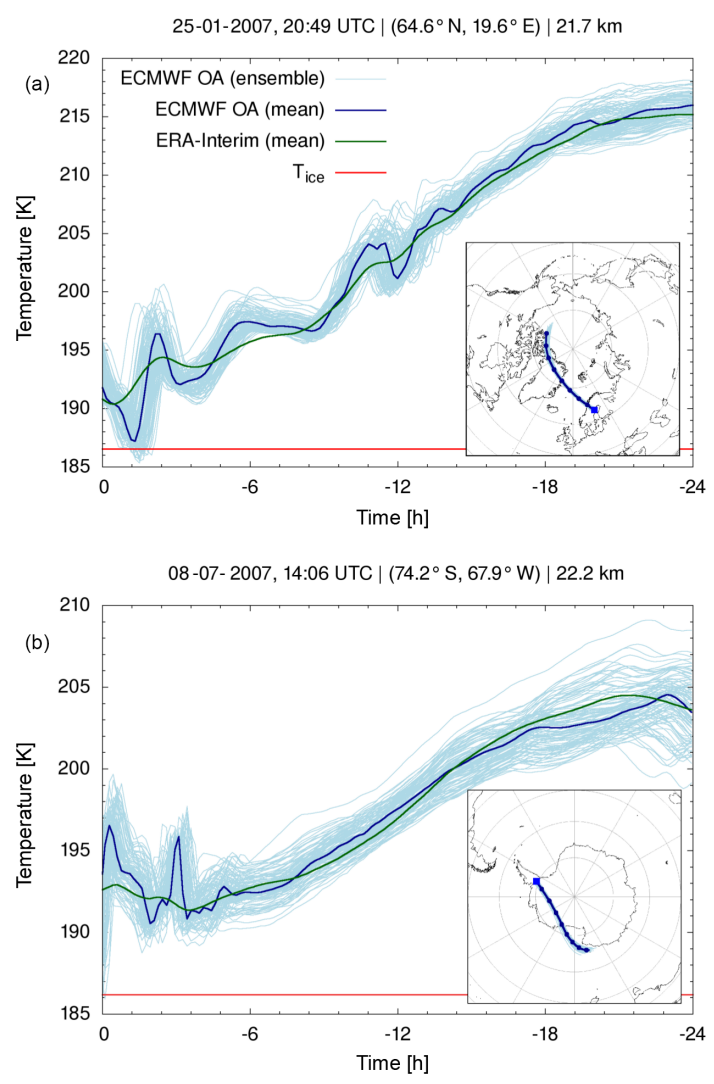

Figure 13. Temperature time series from the backward trajectory calculations for two of the case studies presented in Fig. 11. See plot titles for the time and location of MIPAS detections of ice PSCs that are used to define the trajectory seeds. Note that the time is displayed on a reversed $x$ axis with the MIPAS detection located at $0 \mathrm{~h}$. The calculations are based on ERA-Interim (green) and ECMWF operational analysis (OA; blue) meteorological data. The inset maps show the trajectory paths. 
Table 4. Southern Hemisphere gravity-wave-induced PSC formation events.

\begin{tabular}{ll|ll}
\hline Date & Source region & Date & Source region \\
\hline $2003-06-11$ & Antarctic Peninsula & $2009-06-02$ & Mac. Robertson Land \\
$2003-06-30$ & Antarctic Peninsula & $2009-06-27$ & Antarctic Peninsula \\
$2003-08-23$ & Transantarctic Mountains & $2009-07-19$ & Antarctic Peninsula \\
$2003-09-10$ & Antarctic Peninsula & $2009-07-24$ & non-orographic \\
$2003-09-16$ & Antarctic Peninsula & $2009-09-10$ & Transantarctic Mountains \\
$2005-06-08$ & Marie Byrd Land & $2010-06-11$ & Antarctic Peninsula \\
$2005-06-14$ & Antarctic Peninsula & $2010-07-21$ & Antarctic Peninsula \\
$2006-06-28$ & Antarctic Peninsula & $2010-07-30$ & Marie Byrd Land \\
$2007-07-08$ & Antarctic Peninsula & $2010-08-16$ & Antarctic Peninsula \\
$2007-08-04$ & Transantarctic Mountains & $2011-06-24$ & Enderby Land \\
$2007-08-16$ & Antarctic Peninsula & $2011-06-26$ & Antarctic Peninsula \\
$2007-09-10$ & Antarctic Peninsula & $2011-08-05$ & Antarctic Peninsula \\
$2008-05-29$ & Antarctic Peninsula & & \\
$2008-07-25$ & Transantarctic Mountains & & \\
$2008-08-29$ & Mac. Robertson Land & & \\
$2008-09-12$ & Antarctic Peninsula & & \\
$2008-09-22$ & Antarctic Peninsula & & \\
\hline
\end{tabular}

tion of events by means of the visual inspection of the AIRS and MIPAS maps, and stronger winds in the Southern Hemisphere, which make waves more visible in the AIRS data. In the Southern Hemisphere, most events are found near the Antarctic Peninsula (20 events), followed by the Transantarctic Mountains (4) and other places in coastal Antarctica; in the Northern Hemisphere, most events are found near Greenland (5), Iceland (4), and the Scandinavian Mountains (4). The dates of the events and possible source regions of gravity wave activity are listed in Tables 3 and 4 . The tables provide suggestions for possible case studies that could be explored in future work, e.g., by means of Lagrangian trajectory analyses. The large number of events identified here is promising and supports the conclusion that gravity-wave-induced PSC formation plays an important role in polar ozone chemistry. It shows that the AIRS record of gravity wave activity in the lower stratosphere is a valuable complementary resource that can be used to study this process in more detail.

\section{Summary and conclusions}

We introduced a new long-term satellite record of gravity wave activity in the lower stratosphere at mid- and high latitudes. The data set was compiled to support studies on the influence of small-scale temperature fluctuations due to gravity waves on PSC formation. The record was derived from AIRS/Aqua observations between January 2003 and December 2012. Gravity wave activity is measured in terms of detrended and noise-corrected $15 \mu \mathrm{m}$ brightness temperature variances on a daily basis. We discussed the characteristics of the AIRS channels selected for this analysis in terms of vertical coverage, wavelength sensitivity, and measurement noise. The analysis of temporal patterns of the AIRS grav- ity wave observations revealed a strong seasonal cycle with wintertime maxima at both Northern and Southern Hemisphere mid- and high latitudes. The analysis of spatial patterns showed that the wave activity is mostly related to orographic, jet, and storm sources. The observed patterns of wave activity agree well with those reported in other climatological studies of global gravity wave activity using AIRS observations (Gong et al., 2012; Hoffmann et al., 2013, 2014). The observed gravity wave activity is closely correlated with zonal winds at the $30 \mathrm{hPa}$ level, which we attribute to the AIRS observational filter. Typically, a background wind of at least $10-20 \mathrm{~m} \mathrm{~s}^{-1}$ is required to foster the propagation of gravity waves with long vertical wavelengths into the lower stratosphere, which are best visible to AIRS. Small vertical wavelengths are associated with significant attenuation of the observed brightness temperature perturbations. This attenuation needs to be taken into account if the AIRS data are compared with other measurements or model results. This can be achieved by convolving temperature perturbation profiles from the comparative data with the AIRS weighting functions. Alternatively, the brightness temperature perturbations can be scaled up to estimate true wave amplitudes, but this requires information on the vertical wavelength for any particular case.

We discussed two applications of the new AIRS longterm record of gravity wave activity. The first application is an evaluation of explicitly resolved gravity waves in the ECMWF meteorological data products. We found that observed and simulated gravity wave patterns agree well in extent and shape. However, the amplitudes of the shorthorizontal and long-vertical wavelength gravity waves that are best visible to AIRS are typically underestimated by a factor of 2-3 in the ECMWF operational analysis. This is 
in line with the results of Schroeder et al. (2009) and Jewtoukoff et al. (2015), who validated temperature fluctuations and gravity wave momentum fluxes in the ECMWF operational analysis with infrared limb sounding measurements and superpressure balloon observations, respectively. Both studies attributed the underestimation of gravity wave amplitudes and momentum fluxes to the spatial truncation of the ECMWF model. The second application presented here is a survey of gravity-wave-induced PSC formation events based on joint AIRS and MIPAS observations. Envisat MIPAS observations from 2003 to 2012 revealed nearly 50 events of PSC detection at synoptic-scale temperatures well above the PSC existence and formation thresholds. In many cases, we found that the detections occurred downstream of source regions with gravity wave activity, as revealed by AIRS observations. The large number of events found in this survey confirms that gravity-wave-induced PSC formation is indeed an important process in polar ozone chemistry. The events found here can be explored in more detail by means of Lagrangian trajectory analyses in future work.

\section{Data availability}

AIRS data are distributed by the NASA Goddard Earth Sciences Data Information and Services Center (AIRS Science Team and Chahine, 2007). CALIOP data are distributed by the NASA Langley Research Center, Atmospheric Science Data Center. Envisat MIPAS Level 1b data are distributed by the European Space Agency. The ERA-Interim reanalysis (Dee et al., 2011) and the operational analysis were obtained from the European Centre for Medium-Range Weather Forecasts. The ETOPO2v2 data set was obtained from the US Department of Commerce, National Oceanic and Atmospheric Administration, National Geophysical Data Center (National Geophysical Data Center, 2006). Interested scientists can obtain access to the complete AIRS gravity wave data set introduced in this paper by contacting the leading author.

Competing interests. The authors declare that they have no conflict of interest.

Acknowledgements. M. Joan Alexander and Laura A. Holt acknowledge the NASA Goddard Space Flight Center for support (grant no. NNX14AO76G).

The article processing charges for this open-access publication were covered by a Research

Centre of the Helmholtz Association.

Edited by: H. Wernli

Reviewed by: two anonymous referees

\section{References}

AIRS Science Team and Chahine, M.: AIRS/Aqua L1B Infrared (IR) geolocated and calibrated radiances V005, version 005, Greenbelt, MD, USA, Goddard Earth Sciences Data and Information Services Center (GES DISC), available at: http://disc. gsfc.nasa.gov/datacollection/AIRIBRAD_005.html (last access: 31 December 2015), 2007.

Alexander, M. J. and Barnet, C. D.: Using satellite observations to constrain gravity wave parameterizations for global models, J. Atmos. Sci., 64, 1652-1665, 2007.

Alexander, M. J. and Grimsdell, A. W.: Seasonal cycle of orographic gravity wave occurrence above small islands in the Southern Hemisphere: Implications for effects on the general circulation, J. Geophys. Res., 118, 11589-11599, 2013.

Alexander, M. J. and Pfister, L.: Gravity wave momentum flux in the lower stratosphere over convection, Geophys. Res. Lett., 22, 2029-2032, 1995.

Alexander, S. P., Klekociuk, A. R., Pitts, M. C., McDonald, A. J., and Arevalo-Torres, A.: The effect of orographic gravity waves on Antarctic polar stratospheric cloud occurrence and composition, J. Geophys. Res., 116, D06109, doi:10.1029/2010JD015184, 2011.

Alexander, S. P., Klekociuk, A. R., McDonald, A. J., and Pitts, M. C.: Quantifying the role of orographic gravity waves on polar stratospheric cloud occurrence in the Antarctic and the Arctic, J. Geophys. Res., 118, 11493-11507, 2013.

Aumann, H. H., Chahine, M. T., Gautier, C., Goldberg, M. D., Kalnay, E., McMillin, L. M., Revercomb, H., Rosenkranz, P. W., Smith, W. L., Staelin, D. H., Strow, L. L., and Susskind, J.: AIRS/AMSU/HSB on the Aqua Mission: Design, Science Objective, Data Products, and Processing Systems, IEEE T. Geosci. Remote Sens., 41, 253-264, 2003.

Aumann, H. H., Broberg, S., Elliott, D., Gaiser, S., and Gregorich, D.: Three years of Atmospheric Infrared Sounder radiometric calibration validation using sea surface temperatures, J. Geophys. Res., 111, D16S90, doi:10.1029/2005JD006822, 2006.

Baumgaertner, A. J. G. and McDonald, A. J.: A gravity wave climatology for Antarctica compiled from Challenging Minisatellite Payload/Global Positioning System (CHAMP/GPS) radio occultations, J. Geophys. Res., 112, D05103, doi:10.1029/2006JD007504, 2007.

Browell, E. V., Butler, C. F., Ismail, S., Robinette, P. A., Carter, A. F., Higdon, N. S., Toon, O. B., Schoeberl, M. R., and Tuck, A. F.: Airborne lidar observations in the wintertime Arctic stratosphere: Polar stratospheric clouds, Geophys. Res. Lett., 17, 385388, 1990.

Campbell, J. R. and Sassen, K.: Polar stratospheric clouds at the South Pole from 5 years of continuous lidar data: Macrophysical, optical, and thermodynamic properties, J. Geophys. Res., 113, D20204, doi:10.1029/2007JD009680, 2008.

Carslaw, K., Luo, B., Clegg, S., Peter, T., Brimblecombe, P., and Crutzen, P.: Stratospheric aerosol growth and $\mathrm{HNO}_{3}$ gas phase depletion from coupled $\mathrm{HNO}_{3}$ and water uptake by liquid particles, Geophys. Res. Lett., 21, 2479-2482, 1994.

Carslaw, K., Wirth, M., Tsias, A., Luo, B., Dörnbrack, A., Leutbecher, M., Volkert, H., Renger, W., Bacmeister, J., and Peter, T.: Particle microphysics and chemistry in remotely observed mountain polar stratospheric clouds, J. Geophys. Res., 103, 57855796, 1998a. 
Carslaw, K. S., Wirth, M., Tsias, A., Luo, B. P., Dörnbrack, A., Leutbecher, M., Volkert, H., Renger, W., Bacmeister, J. T., Reimer, E., and Peter, T.: Increased stratospheric ozone depletion due to mountain-induced atmospheric waves, Nature, 391, 675-678, 1998b.

Chahine, M. T., Pagano, T. S., Aumann, H. H., Atlas, R., Barnet, C., Blaisdell, J., Chen, L., Divakarla, M., Fetzer, E. J., Goldberg, M., Gautier, C., Granger, S., Hannon, S., Irion, F. W., Kakar, R., Kalnay, E., Lambrigtsen, B. H., Lee, S., Marshall, J. L., McMillan, W. W., McMillin, L., Olsen, E. T., Revercomb, H., Rosenkranz, P., Smith, W. L., Staelin, D., Strow, L. L., Susskind, J., Tobin, D., Wolf, W., and Zhou, L.: AIRS: improving weather forecasting and providing new data on greenhouse gases, B. Am. Meteorol. Soc., 87, 911-926, 2006.

Dee, D. P., Uppala, S. M., Simmons, A. J., Berrisford, P., Poli, P., Kobayashi, S., Andrae, U., Balmaseda, M. A., Balsamo, G., Bauer, P., Bechtold, P., Beljaars, A. C. M., van de Berg, I., Biblot, J., Bormann, N., Delsol, C., Dragani, R., Fuentes, M., Greer, A. J., Haimberger, L., Healy, S. B., Hersbach, H., Holm, E. V., Isaksen, L., Kallberg, P., Kohler, M., Matricardi, M., McNally, A. P., Mong-Sanz, B. M., Morcette, J.-J., Park, B.-K., Peubey, C., de Rosnay, P., Tavolato, C., Thepaut, J. N., and Vitart, F.: The ERAInterim reanalysis: Configuration and performance of the data assimilation system, Q. J. Roy. Meteorol. Soc., 137, 553-597, 2011.

Di Liberto, L., Lehmann, R., Tritscher, I., Fierli, F., Mercer, J. L., Snels, M., Di Donfrancesco, G., Deshler, T., Luo, B. P., Grooß, J.-U., Arnone, E., Dinelli, B. M., and Cairo, F.: Lagrangian analysis of microphysical and chemical processes in the Antarctic stratosphere: a case study, Atmos. Chem. Phys., 15, 6651-6665, doi:10.5194/acp-15-6651-2015, 2015.

Dörnbrack, A., Leutbecher, M., Kivi, R., and Kyrö, E.: Mountainwave-induced record low stratospheric temperatures above northern Scandinavia, Tellus, 51, 951-963, 1999.

Dörnbrack, A., Birner, T., Fix, A., Flentje, H., Meister, A., Schmid, H., Browell, E. V., and Mahoney, M. J.: Evidence for inertia gravity waves forming polar stratospheric clouds over Scandinavia, J. Geophys. Res., 107, 8287, doi:10.1029/2001JD000452, 2002.

Durran, D. R. and Klemp, J. B.: Another look at downslope winds. Part II: nonlinear amplification beneath wave-overturning layers, J. Atmos. Sci., 44, 3402-3412, 1987.

Eckermann, S. D., Wu, D. L., Doyle, J. D., Burris, J. F., McGee, T. J., Hostetler, C. A., Coy, L., Lawrence, B. N., Stephens, A., McCormack, J. P., and Hogan, T. F.: Imaging gravity waves in lower stratospheric AMSU-A radiances, Part 2: Validation case study, Atmos. Chem. Phys., 6, 3343-3362, doi:10.5194/acp-63343-2006, 2006.

Eckermann, S. D., Hoffmann, L., Höpfner, M., Wu, D. L., and Alexander, M. J.: Antarctic NAT PSC belt of June 2003: Observational validation of the mountain wave seeding hypothesis, Geophys. Res. Lett., 36, L02807, doi:10.1029/2008GL036629, 2009.

Engel, I., Luo, B. P., Pitts, M. C., Poole, L. R., Hoyle, C. R., Grooß, J.-U., Dörnbrack, A., and Peter, T.: Heterogeneous formation of polar stratospheric clouds - Part 2: Nucleation of ice on synoptic scales, Atmos. Chem. Phys., 13, 10769-10785, doi:10.5194/acp13-10769-2013, 2013.

Fischer, H., Birk, M., Blom, C., Carli, B., Carlotti, M., von Clarmann, T., Delbouille, L., Dudhia, A., Ehhalt, D., Endemann, M.,
Flaud, J. M., Gessner, R., Kleinert, A., Koopman, R., Langen, J., López-Puertas, M., Mosner, P., Nett, H., Oelhaf, H., Perron, G., Remedios, J., Ridolfi, M., Stiller, G., and Zander, R.: MIPAS: an instrument for atmospheric and climate research, Atmos. Chem. Phys., 8, 2151-2188, doi:10.5194/acp-8-2151-2008, 2008.

Fritts, D. C. and Alexander, M. J.: Gravity wave dynamics and effects in the middle atmosphere, Rev. Geophys., 41, 1003, doi:10.1029/2001RG000106, 2003.

Gong, J., Wu, D. L., and Eckermann, S. D.: Gravity wave variances and propagation derived from AIRS radiances, Atmos. Chem. Phys., 12, 1701-1720, doi:10.5194/acp-12-1701-2012, 2012.

Grimsdell, A. W., Alexander, M. J., May, P. T., and Hoffmann, L.: Model study of waves generated by convection with direct validation via satellite, J. Atmos. Sci., 67, 1617-1631, 2010.

Grooß, J.-U., Engel, I., Borrmann, S., Frey, W., Günther, G., Hoyle, C. R., Kivi, R., Luo, B. P., Molleker, S., Peter, T., Pitts, M. C., Schlager, H., Stiller, G., Vömel, H., Walker, K. A., and Müller, R.: Nitric acid trihydrate nucleation and denitrification in the Arctic stratosphere, Atmos. Chem. Phys., 14, 1055-1073, doi:10.5194/acp-14-1055-2014, 2014.

Hanson, D. and Mauersberger, K.: Laboratory studies of the nitric acid trihydrate: Implications for the south polar stratosphere, Geophys. Res. Lett., 15, 855-858, 1988.

Hendricks, E. A., Doyle, J. D., Eckermann, S. D., Jiang, Q., and Reinecke, P. A.: What is the source of the stratospheric gravity wave belt in austral winter?, J. Atmos. Sci., 71, 1583-1592, 2014.

Hindley, N. P., Wright, C. J., Smith, N. D., and Mitchell, N. J.: The southern stratospheric gravity wave hot spot: individual waves and their momentum fluxes measured by COSMIC GPS-RO, Atmos. Chem. Phys., 15, 7797-7818, doi:10.5194/acp-15-77972015, 2015.

Hitchman, M. H., Buker, M. L., Tripoli, G. J., Browell, E. V., Grant, W. B., McGee, T. J., and Burris, J. F.: Nonorographic generation of Arctic polar stratospheric clouds during December 1999, J. Geophys. Res., 108, 8325, doi:10.1029/2001JD001034, 2003.

Hoffmann, L. and Alexander, M. J.: Retrieval of stratospheric temperatures from Atmospheric Infrared Sounder radiance measurements for gravity wave studies, J. Geophys. Res., 114, D07105, doi:10.1029/2008JD011241, 2009.

Hoffmann, L. and Alexander, M. J.: Occurrence frequency of convective gravity waves during the North American thunderstorm season, J. Geophys. Res., 115, D20111, doi:10.1029/2010JD014401, 2010.

Hoffmann, L., Xue, X., and Alexander, M. J.: A global view of stratospheric gravity wave hotspots located with Atmospheric Infrared Sounder observations, J. Geophys. Res., 118, 416-434, 2013.

Hoffmann, L., Alexander, M. J., Clerbaux, C., Grimsdell, A. W., Meyer, C. I., Rößler, T., and Tournier, B.: Intercomparison of stratospheric gravity wave observations with AIRS and IASI, Atmos. Meas. Tech., 7, 4517-4537, doi:10.5194/amt-7-4517-2014, 2014.

Hoffmann, L., Grimsdell, A. W., and Alexander, M. J.: Stratospheric gravity waves at Southern Hemisphere orographic hotspots: 2003-2014 AIRS/Aqua observations, Atmos. Chem. Phys., 16, 9381-9397, doi:10.5194/acp-16-9381-2016, 2016 a.

Hoffmann, L., Rößler, T., Griessbach, S., Heng, Y., and Stein, O.: Lagrangian transport simulations of volcanic sulfur dioxide 
emissions: impact of meteorological data products, J. Geophys. Res., 121, 4651-4673, doi:10.1002/2015JD023749, 2016b.

Holton, J. R.: The role of gravity wave induced drag and diffusion on the momentum budget of the mesosphere, J. Atmos. Sci., 39, 791-799, 1982.

Höpfner, M., Larsen, N., Spang, R., Luo, B. P., Ma, J., Svendsen, S. H., Eckermann, S. D., Knudsen, B., Massoli, P., Cairo, F., Stiller, G., v. Clarmann, T., and Fischer, H.: MIPAS detects Antarctic stratospheric belt of NAT PSCs caused by mountain waves, Atmos. Chem. Phys., 6, 1221-1230, doi:10.5194/acp-6-1221-2006, 2006a.

Höpfner, M., Luo, B. P., Massoli, P., Cairo, F., Spang, R., Snels, M., Di Donfrancesco, G., Stiller, G., von Clarmann, T., Fischer, H., and Biermann, U.: Spectroscopic evidence for NAT, STS, and ice in MIPAS infrared limb emission measurements of polar stratospheric clouds, Atmos. Chem. Phys., 6, 1201-1219, doi:10.5194/acp-6-1201-2006, 2006b.

Hoyle, C. R., Engel, I., Luo, B. P., Pitts, M. C., Poole, L. R., Grooß, J.-U., and Peter, T.: Heterogeneous formation of polar stratospheric clouds - Part 1: Nucleation of nitric acid trihydrate (NAT), Atmos. Chem. Phys., 13, 9577-9595, doi:10.5194/acp13-9577-2013, 2013.

Jewtoukoff, V., Hertzog, A., Plougonven, R., Cámara, A. D. L., and Lott, F.: Comparison of Gravity Waves in the Southern Hemisphere Derived from Balloon Observations and the ECMWF Analyses, J. Atmos. Sci., 72, 3449-3468, 2015.

Kim, S., Chun, H., and Wu, D. L.: A study on stratospheric gravity waves generated by Typhoon Ewiniar: Numerical simulations and satellite observations, J. Geophys. Res., 114, D22104, doi:10.1029/2009JD011971, 2009.

Kohma, M. and Sato, K.: The effects of atmospheric waves on the amounts of polar stratospheric clouds, Atmos. Chem. Phys., 11, 11535-11552, doi:10.5194/acp-11-11535-2011, 2011.

Lambert, A., Santee, M. L., Wu, D. L., and Chae, J. H.: A-train CALIOP and MLS observations of early winter Antarctic polar stratospheric clouds and nitric acid in 2008, Atmos. Chem. Phys., 12, 2899-2931, doi:10.5194/acp-12-2899-2012, 2012.

Lindzen, R. S.: Turbulence and stress due to gravity wave and tidal breakdown, J. Geophys. Res., 86, 9707-9714, 1981.

Marti, J. and Mauersberger, K.: Laboratory simulations of PSC particle formation, Geophys. Res. Lett., 20, 359-362, 1993.

McDonald, A. J., George, S. E., and Woollands, R. M.: Can gravity waves significantly impact PSC occurrence in the Antarctic?, Atmos. Chem. Phys., 9, 8825-8840, doi:10.5194/acp-9-8825-2009, 2009.

McNally, A. P., Watts, P. D., A. Smith, J., Engelen, R., Kelly, G. A., Thépaut, J. N., and Matricardi, M.: The assimilation of AIRS radiance data at ECMWF, Q. J. Roy. Meteorol. Soc., 132, 935957, 2006.

Nastrom, G. D. and Fritts, D. C.: Sources of mesoscale variability of gravity waves, Part I: topographic excitation, J. Atmos. Sci., 49, 101-110, 1992.

National Geophysical Data Center: 2-minute Gridded Global Relief Data (ETOPO2) v2, National Geophysical Data Center, NOAA, doi:10.7289/V5J1012Q (last access: 24 November 2015), 2006.

Noel, V. and Pitts, M.: Gravity wave events from mesoscale simulations, compared to polar stratospheric clouds observed from spaceborne lidar over the Antarctic Peninsula, J. Geophys. Res., 117, D11207, doi:10.1029/2011JD017318, 2012.
Orr, A., Bechtold, P., Scinocca, J., Ern, M., and Janiskova, M.: Improved Middle Atmosphere Climate and Forecasts in the ECMWF Model through a Nonorographic Gravity Wave Drag Parameterization, J. Climate, 23, 5905-5926, 2010.

Orr, A., Hosking, J. S., Hoffmann, L., Keeble, J., Dean, S. M., Roscoe, H. K., Abraham, N. L., Vosper, S., and Braesicke, P.: Inclusion of mountain-wave-induced cooling for the formation of PSCs over the Antarctic Peninsula in a chemistry-climate model, Atmos. Chem. Phys., 15, 1071-1086, doi:10.5194/acp-15-10712015, 2015.

Pawson, S., Naujokat, B., and Labitzke, K.: On the polar stratospheric cloud formation potential of the northern stratosphere, J. Geophys. Res., 100, 23215-23225, 1995.

Pfister, L., Starr, W., Craig, R., Loewenstein, M., and Legg, M.: Small-Scale Motions Observed by Aircraft in the Tropical Lower Stratosphere: Evidence for Mixing and its Relationship to LargeScale Flows, J. Atmos. Sci., 43, 3210-3225, 1986.

Pitts, M. C., Poole, L. R., and Thomason, L. W.: CALIPSO polar stratospheric cloud observations: second-generation detection algorithm and composition discrimination, Atmos. Chem. Phys., 9, 7577-7589, doi:10.5194/acp-9-7577-2009, 2009.

Poole, L. R. and McCormick, M. P.: Airborne lidar observations of Arctic polar stratospheric clouds: Indications of two distinct growth stages, Geophys. Res. Lett., 15, 21-23, 1988.

Poole, L. R. and Pitts, M. C.: Polar stratospheric cloud climatology based on Stratospheric Aerosol Measurement, II observations from 1978 to 1989, J. Geophys. Res., 99, 13083-13089, 1994.

Randel, W., Udelhofen, P., Fleming, E., Geller, M., Gelman, M., Hamilton, K., Karoly, D., Ortland, D., Pawson, S., Swinbank, R., Wu, F., Baldwin, M., Chanin, M.-L., Keckhut, P., Labitzke, K., Remsberg, E., Simmons, A., and Wu, D.: The SPARC Intercomparison of middle atmosphere climatologies, J. Climate, 17, 986-1003, 2004.

Sato, K., Tateno, S., Watanabe, S., and Kawatani, Y.: Gravity wave characteristics in the Southern Hemisphere revealed by a highresolution middle-atmosphere general circulation model, J. Atmos. Sci., 69, 1378-1396, 2012.

Schroeder, S., Preusse, P., Ern, M., and Riese, M.: Gravity waves resolved in ECMWF and measured by SABER, Geophys. Res. Lett., 36, L10805, doi:10.1029/2008GL037054, 2009.

Shibata, T., Sato, K., Kobayashi, H., Yabuki, M., and Shiobara, M.: Antarctic polar stratospheric clouds under temperature perturbation by nonorographic inertia gravity waves observed by micropulse lidar at Syowa Station, J. Geophys. Res., 108, 4105, doi:10.1029/2002JD002713, 2003.

Smith, R. B.: On severe downslope winds, J. Atmos. Sci., 42, $2597-$ 2603, 1985.

Solomon, S.: Stratospheric ozone depletion: A review of concepts and history, Rev. Geophys., 37, 275-316, 1999.

Solomon, S., Garcia, R. R., Rowland, F. S., and Wuebbles, D. J.: On the depletion of Antarctic ozone, Nature, 321, 755-758, 1986.

Spang, R., Remedios, J. J., and Barkley, M. P.: Colour indices for the detection and differentiation of cloud type in infra-red limb emission spectra, Adv. Space Res., 33, 1041-1047, 2004.

Spang, R., Remedios, J. J., Kramer, L. J., Poole, L. R., Fromm, M. D., Müller, M., Baumgarten, G., and Konopka, P.: Polar stratospheric cloud observations by MIPAS on ENVISAT: detection method, validation and analysis of the northern hemi- 
sphere winter 2002/2003, Atmos. Chem. Phys., 5, 679-692, doi:10.5194/acp-5-679-2005, 2005.

Spang, R., Arndt, K., Dudhia, A., Höpfner, M., Hoffmann, L., Hurley, J., Grainger, R. G., Griessbach, S., Poulsen, C., Remedios, J. J., Riese, M., Sembhi, H., Siddans, R., Waterfall, A., and Zehner, C.: Fast cloud parameter retrievals of MIPAS/Envisat, Atmos. Chem. Phys., 12, 7135-7164, doi:10.5194/acp-12-71352012, 2012.

Spang, R., Hoffmann, L., Höpfner, M., Griessbach, S., Müller, R., Pitts, M. C., Orr, A. M. W., and Riese, M.: A multi-wavelength classification method for polar stratospheric cloud types using infrared limb spectra, Atmos. Meas. Tech., 9, 3619-3639, doi:10.5194/amt-9-3619-2016, 2016.

Steele, H., Hamill, P., McCormick, M., and Swissler, T.: The formation of polar stratospheric clouds, J. Atmos. Sci., 40, 2055-2068, 1983.

Stephan, C. and Alexander, M. J.: Realistic simulations of atmospheric gravity waves over the continental US using precipitation radar data, J. Adv. Model. Earth Sys., 7, 823-835, 2015.

Stockwell, R. G., Mansinha, L., and Lowe, R.: Localization of the complex spectrum: the S transform, IEEE T. Signal Proces., 44, 998-1001, 1996.

Toon, O. B., Hamill, P., Turco, R. P., and Pinto, J.: Condensation of $\mathrm{HNO}_{3}$ and $\mathrm{HCl}$ in the winter polar stratospheres, Geophys. Res. Lett., 13, 1284-1287, 1986.

Tsuda, T., Murayama, Y., Wiryosumarto, H., Harijono, S. W. B., and Kato, S.: Radiosonde observations of equatorial atmosphere dynamics over Indonesia, 2. Characteristics of gravity waves, J. Geophys. Res., 99, 10507-10516, 1994.

Winker, D. M., Pelon, J., Coakley, J. A., Ackerman, S. A., Charlson, R. J., Colarco, P. R., Flamant, P., Fu, Q., Hoff, R. M., Kittaka, C., Kubar, T. L., Le Treut, H., McCormick, M. P., Mégie, G., Poole, L., Powell, K., Trepte, C., Vaughan, M. A., and Wielicki, B. A.: The CALIPSO Mission: A Global 3D View of Aerosols and Clouds, B. Am. Meteorol. Soc., 91, 1211-1229, 2010.
Worsnop, D. R., Zahniser, M. S., Fox, L. E., and Wofsy, S. C.: Vapor pressures of solid hydrates of nitric acid: Implications for polar stratospheric clouds, Science, 259, 71-74, 1993.

$\mathrm{Wu}$, D. L.: Mesoscale gravity wave variances from AMSU-A radiances, Geophys. Res. Lett., 31, L12114, doi:10.1029/2004GL019562, 2004.

Wu, D. L. and Eckermann, S. D.: Global gravity wave variances from Aura MLS: characteristics and interpretation, J. Atmos. Sci., 65, 3695-3718, 2008.

Wu, D. L. and Jiang, J. H.: MLS observations of atmospheric gravity waves over Antarctica, J. Geophys. Res., 107, 4773, doi:10.1029/2002JD002390, 2002.

Wu, D. L. and Zhang, F.: A study of mesoscale gravity waves over the North Atlantic with satellite observations and a mesoscale model, J. Geophys. Res., 109, D22104, doi:10.1029/2004JD005090, 2004.

Wu, J. F., Xue, X. H., Hoffmann, L., Dou, X. K., Li, H. M., and Chen, T. D.: A case study of typhoon-induced gravity waves and the orographic impacts related to Typhoon Mindulle (2004) over Taiwan, J. Geophys. Res., 120, 9193-9207, 2015.

Zhang, R., Wooldridge, P. J., and Molina, M. J.: Vapor pressure measurements for the $\mathrm{H}_{2} \mathrm{SO}_{4} / \mathrm{HNO}_{3} / \mathrm{H}_{2} \mathrm{O}$ and $\mathrm{H}_{2} \mathrm{SO}_{4} / \mathrm{HCl} / \mathrm{H}_{2} \mathrm{O}$ systems: Incorporation of stratospheric acids into background sulfate aerosols, J. Phys. Chem., 97, 8541-8548, 1993. 